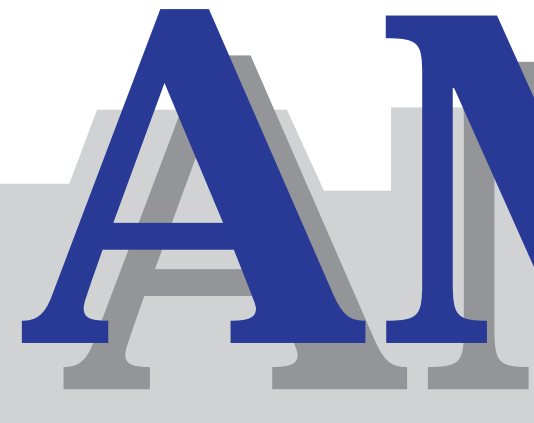

Acta Médica Costarricense

Fundada en 1957 por el Dr. Rodolfo Céspedes Fonseca

\title{
Publicación de la Federación Centroamericana y del Caribe de Neumología y Cirugía de Tórax
}

\author{
Volumen 3 № 1
}

Costa Rica, Marzo 2003

Publicación Científica Oficial del Colegio de

Médicos y Cirujanos de Costa Rica

Tel.: (506) 232-3433 / Fax: (506) 232-2406 / Apdo. 548-1000 Sabana Sur, San José, Costa Rica

Dirección electrónica: www.medicos.sa cr
Volumen 45

Suplemento 1

Marzo 2003 
ISSN 0001-6002/2003/Supl.1/3

Acta Médica Costarricense,(C2003

Colegio de Médicos y Cirujanos

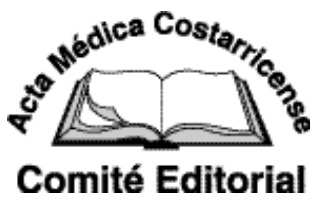

Apartado 548-1000 San José, Costa Rica. Tel.: (506) 232-3433. Fax: (506) 232-2406. Correo electrónico: medicos@racsa.co.cr Dirección electrónica: www.medicos.sa.cr

\section{Comité Editorial}

Editora en Jefe

María Paz León Bratti

Editora

Henriette Raventós Vorst

Editor

Carlos Salazar Vargas

Editor

Oscar Porras Madrigal

Editor

Pablo Monge Zeledón

Editor

Abed Raduan Mohammad Hasan

Secretaria: Dylana Alvarado C. Asesora en Filología: Marcela E. Hidalgo

\section{Editorial}

El presente suplemento de Acta Médica Costarricense es el primer esfuerzo conjunto que hace el Comité Editorial de la Revista con una Asociación Médica, en este caso, la Asociación Costarricense de Neumología y Cirugía de Tórax, con el fin de difundir a nivel nacional e internacional las normas que tiene dicha asociación en el manejo de las principales patologías que le conciernen a esa especialidad.

El comité editorial de AMC considera de gran importancia que la revista sea utilizada como medio informativo de las actividades científicas de las Asociaciones Médicas inscritas en el Colegio de Médicos y Cirujanos; especialmente, en la propagación de normas y protocolos de manejo que faciliten a los médicos generales y los médicos de otras especialidades la identificación temprana, diagnóstico, manejo o referencia temprana de las patologías correspondientes a la especialidad de cada asociación.

El fin de la revista AMC, como revista científica oficial de nuestro colegio, es el brindar información actualizada y de alta calidad científica al cuerpo médico general y, de esta manera, convertirse en un medio útil para la publicación de la investigación científica que se realiza a nivel nacional. Sin embargo, lo más importante es que la revista, en la búsqueda de estos objetivos, no pierda de vista que su responsabilidad es serle útil al cuerpo médico nacional, razón última de todas las actividades de nuestro colegio.

La difusión de este tipo de publicación conjunta se convierte en una novedosa e importante actividad de educación médica continua, al hacerla llegar a través de AMC, a más de 5000 médicos a nivel nacional y ponerse a disposición general en texto completo a través de la internet.

Este Comité Editorial desea aprovechar la oportunidad para felicitar y exaltar el esfuerzo de la Asociación Costarricense de Neumología y Cirugía de Torax al producir este extenso documento que desea pautar el manejo de un grupo tan importante de pacientes y ayudarle al médico general y los especialistas en otras áreas en su toma de decisiones. Esperamos que el ejemplo sea imitado por muchas otras asociaciones en el futuro para el provecho del cuerpo médico nacional y que éstas tengan en cuenta a su revista para la difusión de las mismas. Por lo tanto, no nos queda más que ponernos a su servicio, como siempre lo hemos hecho, para brindarles nuestra ayuda y apoyo como medio científico de difusión, en todas las etapas de proceso.

Estamos seguros que los médicos costarricenses y extranjeros encontrarán en esta normas una excelente referencia así que esperamos obtengan de este suplemento gran provecho.

\author{
María Paz León Bratti \\ Editora en Jefe \\ Acta Médica Costarricense
}


ISSN 0001-6002/2003/Supl.1/4

Acta Médica Costarricense,(C2003

Colegio de Médicos y Cirujanos

\section{Asociación Costarricense de Neumología y Cirugía de Tórax}

Junta Directiva 2001-2003

Presidente

Dr. Ronald A. Chacón Chaves

Vicepresidente

Dr. Raúl Valverde Robert

Secretario

Dr. Roberto Vargas Gillén

Tesorero

Dr. Mario Ingianna Acuña

I Vocal

Dr. Carlos Jaime Alfaro Rodríguez

II Vocal

Dr. John Miranda Chavarría

Fiscal

Dr. José A. Mainieri Hidalgo

\section{Introducción}

El presente documento ha sido elaborado por la Asociación Costarricense de Neumología y Cirugía de Tórax con el fin de ofrecer al cuerpo médico nacional y centroamericano un instrumento con los lineamientos que consideramos deben ser seguidos en el abordaje y tratamiento de algunas patologías pulmonares y torácicas.

La Asociación agradece a todos sus miembros que dedicaron su tiempo y esfuerzo para la elaboración de este documento. La mayoría de los capítulos fueron preparados por miembros la Asociación. El capítulo de Neumonía Adquirida en la Comunidad fue preparado por un equipo multidisciplinario de expertos especialistas involucrados en el manejo de estos pacientes. El capítulo de Fibrosis Quística resume los lineamientos que se siguen en el manejo y tratamiento de estos pacientes en el Hospital Nacional de Niños en Costa Rica.

Esperamos este documento sea de utilidad tanto para el médico general como el especialista y esperamos que con sus comentarios y sugerencias podamos mejorar ediciones subsecuentes del mismo.

Este documento se presenta como el tercer volumen de la Revista de la Federación Centroamericana de Neumología y Cirugía de Tórax. Agradecemos al Comité Editorial de Acta Médica Costarricense por publicar este suplemento dentro de su revista, lo cual favorecerá su difusión entre todo el cuerpo médico nacional. Además agradecemos a las compañías Merck Sharp and Dohme y Glaxo Smith Kline su apoyo económico para esta publicación.

Dr. Ronald A. Chacón Chaves

Presidente 2001-2003

Asociación Costarricense de Neumología y Cirugía de Tórax 
ISSN 0001-6002/2003/Sup.1/5-22

Acta Médica Costarricense,(C2003

Colegio de Médicos y Cirujanos

\title{
Asma Bronquial
}

\author{
Wing Ching Chan-Cheng, Marlene Jiménez-Carro, Sofía Antillón-Morales, Mario Ingianna-Acuña, \\ Carlos Jaime Alfaro-Rodríguez, Georgina López-Odio, Ted Mitchell-Brumley \\ Asociación Costarricense de Neumología y Cirugía de Tórax
}

\section{Definición de asma:}

Es un desorden inflamatorio crónico en la cual muchas células y elementos celulares juegan un rol. La inflamación crónica causa un incremento asociado de hiperreactividad bronquial que produce cuadros recurrentes de sibilancias, disnea, apretazón de pecho y tos; particularmente en la noche y en las primeras horas de la mañana. Estos episodios están asociados a una obstrucción de las vías aéreas en forma generalizada y de grado variable la cual es reversible en forma espontánea o con tratamiento.

Inflamación: Es el resultado de una cascada de eventos que involucran diferentes elementos celulares como linfocitos $\mathrm{T}$, eosinófilos, mastocitos, neutrófilos y macrófagos, además de mediadores y factores que interactúan entre sí. Esto produce la lesión y reparación del epitelio bronquial que conlleva a cambios estructurales y funcionales que resultan en obstrucción y remodelación de las vías aéreas.

Hiperreactividad: Es una condición en la cual las vías aéreas se estrechan exageradamente en respuesta a una variedad de estímulos.

Obstrucción: Aumento de la resistencia al flujo aéreo secundario a cambios inflamatorios en la vía aérea (contracción del músculo liso, edema, infiltrado inflamatorio de tipo celular y moco).

\section{Diagnóstico}

El asma bronquial alrededor del mundo es una entidad clínica que se encuentra subdiagnosticada especialmente en niños, ancianos, individuos con tos recurrente e individuos con exposición ocupacional. Lo anterior se ha atribuido en parte a lo intermitente de los síntomas que favorecen la tolerancia de los mismos por parte del paciente y por el carácter inespecífico de ellos.

Para su diagnóstico se utiliza la historia clínica y las pruebas de función pulmonar (que pueden determinar el carácter reversible de las anormalidades). La medición de síntomas y de la función pulmonar son parámetros importantes para valorar las características del asma bronquial para cada paciente.
Con respecto a la historia clínica se debe considerar el diagnóstico cuando hay disnea episódica, sibilancias, sensación de opresión torácica, cuando hay historia de variabilidad estacional, atopia y antecedentes familiares de asma.

Los parámetros más importantes en la medición de la función pulmonar para determinar si existe limitación al flujo aéreo en personas mayores de 5 años son: Volumen Espiratorio Forzado al primer segundo (VEF1), Capacidad Vital Forzada (CVF), Relación VEF1/CVF y Flujo Espiratorio Forzado (FEF) o flujo pico .

El examen físico aporta poco al diagnóstico; sin embargo, la alteración más frecuentemente encontrada a través de él es la presencia de sibilancias.

Se han utilizado en estudios epidemiológicos algunos cuestionarios con preguntas claves que orientan hacia el diagnóstico de la enfermedad:

\section{Cuestionario:}

¿Tiene el paciente un episodio o episodios recurrentes de sibilancias?

¿Tiene el paciente tos molesta durante la noche?

¿Tiene el paciente tos o sibilancias después del ejercicio, risa o llanto?

¿Tiene el paciente opresión torácica, tos o sibilancias después de la inhalación de alergenos, olores fuertes, contaminantes del aire y otros?

¿Se van "hacia el pecho" o duran más de 10 días los cuadros gripales?

¿Mejoran los síntomas con broncodilatadores y/o esteroides?

\section{Medición de la función pulmonar}

La medición de la reversibilidad provee de una evidencia directa de la limitación al flujo de aire y la medición de la variabilidad provee de una evidencia indirecta de la hiperreactividad de las vías aéreas que son a su vez la consecuencia del trastorno inflamatorio. 


\section{Espirometría}

Es un procedimiento reproducible, esfuerzo dependiente, influido por la instrucción previa al paciente. La espirometría esta limitada a algunos centros clínicos pues es un equipo relativamente caro. Sus valores predichos se afectan por la edad (sobre todo las extremas), género, estatura y raza.

Se toman los valores más altos de dos a tres mediciones. Tiene la desventaja que pierde sensibilidad con valores de VEF1 $<1$ litro; además el VEF1 se puede alterar por otras enfermedades diferentes a las que producen limitación al flujo de aire, por lo que la relación del VEF1/CVF es importante para establecer el diagnóstico, por ejemplo, en adultos si este valor es $<$ de $80 \%$ y en niños si es menor de $90 \%$ es sugestivo de limitación al flujo de aire.

El criterio diagnóstico de asma es mejoría del VEF1 mayor o igual al 12\% del predicho que puede ser espontánea, posterior a inhalación de Beta 2 agonistas o después de un ciclo de esteroides.

La espirometría sirve también para valorar la actividad del asma (severidad), valorar la progresión del asma y la respuesta al tratamiento en el manejo a largo plazo, este estudio es mucho más sensible que el Flujo pico sobre todo en ciertas poblaciones (adulto mayor) y ante la presencia de otras patologías bronco-pleuro-pulmonares asociadas.

\section{Flujo Espiratorio Forzado (FEF) o Flujo Pico}

Es una ayuda importante en el diagnóstico y tratamiento del asma. Se puede utilizar a nivel del hogar, es barato y portátil. Es un procedimiento reproducible, dependiente del esfuerzo, influenciado por la educación del paciente.

Sus valores no siempre se correlacionan con otros métodos que evalúan la función pulmonar para determinar la severidad del cuadro. Debe compararse siempre con el mejor valor obtenido de previo para cada paciente.

Para hacer diagnóstico se requiere al menos 15\% de mejoría en la medición posterior a inhalación con broncodilatadores 0 después de un ciclo de esteroides.

La medición del Flujo Pico es útil también pues permite la supervisión del asma cuando no hay espirometría disponible, a nivel del hogar permite detectar signos tempranos de deterioro, permite valorar la severidad y la respuesta al tratamiento en el manejo a corto y largo plazo y sirve para detectar no sólo la limitación al flujo de aire sino también la variabilidad en 24 horas.

\section{Flujo Pico: Medición de la variabilidad}

Es un dato indirecto de la hiperreactividad de la vía aérea.

Idealmente se debe tomar muy temprano en la mañana, ya que su medición estaría cerca del valor más bajo; y antes de acostarse pues su resultado estaría cerca del valor más alto.
El mejor método y más fácil para medir la variabilidad es el porcentaje de variabilidad (Se toma una vez al día por una semana) expresado en:

Variabilidad en \%:

El mínimo Flujo Pico matutino prebroncodilatador de la semana

El máximo Flujo Pico personal recientemente registrado

El criterio diagnóstico es cuando se encuentra una variación diaria del $20 \%$ o más; esto hace el diagnóstico de asma.

La magnitud de la variabilidad se correlaciona con la severidad de la enfermedad, sin embargo en asma intermitente o severa intratable la variabilidad del Flujo pico puede no estar presente o haberse perdido. Algunas veces en el asma severa tanto la variabilidad como la reversibilidad se hacen evidentes hasta después de varias semanas después de un curso de esteroides. La monitorización del Flujo pico sirve a corto plazo para establecer el diagnóstico, identificación de factores ambientales desencadenantes, evaluación de cambios en el tratamiento. A largo plazo permite la monitorización de pacientes con asma severa, con mala percepción de la severidad de sus síntomas y con internamientos frecuentes.

\section{Otros métodos diagnósticos}

La hiperreactividad de la vía aérea se puede determinar en pacientes con síntomas sospechosos de asma pero que tienen pruebas de función pulmonar normal, realizando pruebas de bronco provocación a la histamina, metacolina y al esfuerzo físico. Estas mediciones son muy sensibles pero poco especificas, es decir que un test negativo excluye el diagnóstico pero un resultado positivo no necesariamente indica asma, puede tratarse de otras enfermedades como lo son: fibrosis quística (mucoviscidosis), bronquiectasias, EPOC, etc.

La medición de parámetros de la inflamación por métodos no invasivos incluye la detección de eosinófilos en el esputo y de células metacromáticas, también la determinación de los niveles exhalados de óxido nítrico y de monóxido de carbono; sin embargo aún no se ha determinado su utilidad en el diagnóstico del asma.

La medición del estado alérgico a través de las pruebas cutáneas y de los niveles séricos de IgE sirven básicamente para ayudar a detectar factores de riesgo desencadenantes pero no para establecer el diagnóstico.

\section{Diagnóstico diferencial del asma bronquial}

El asma bronquial es una de las enfermedades mas comunes que producen sintomatología respiratoria. Se caracteriza por la demostración de limitación al flujo de aire reversible y variable a través de la espirometría.

En el diagnóstico diferencial se incluyen las siguientes causas: 
Infecciosas: Cuadros gripales, bronquiolitis, neumonía, tuberculosis, gérmenes oportunistas

\section{Otras Enfermedades obstructivas:}

Localizadas: Disfunción de cuerdas vocales, Paresia de cuerda vocal, Cáncer de laringe, traqueal y/o bronquial, Cuerpo extraño, Displasia broncopulmonar.

Generalizadas: Enfermedad pulmonar obstructiva crónica, bronquiolitis obliterante, fibrosis quística, bronquiectasias

\section{Enfermedades restrictivas:}

Pulmonares: Alveolitis alérgica extrínseca, sarcoidosis, alveolitis fibrosante, asbestosis, neumonía eosinofílica

Patología pleural: Derrame pleural, neumotórax

Deformidad de la pared torácica: Xifoescoliosis

Debilidad de los músculos respiratorios
Problemas subdiafragmáticos: Obesidad, Ascitis

\section{Otras Causas de tos crónica:}

Goteo nasal posterior, reflujo gastroesofágico, uso de inhibidores de la ECA, Insuficiencia cardíaca izquierda ("asma cardíaca”)

\section{Grupos especiales que ofrecen dificultades diagnósticas}

En estos casos la medición de la limitación al flujo de aire y de la variabilidad son extremadamente útiles para hacer el diagnóstico. Existen varios grupos importantes, entre ellos los niños, los ancianos, asma ocupacional, el asma estacional y la tos como equivalente asmático.

\section{Clasificación del asma}

El enfoque de la severidad del asma está basado en la sintomatología, el uso de medicación broncodilatadora para el control de los síntomas y la función pulmonar.

\begin{tabular}{|c|c|}
\hline \multicolumn{2}{|r|}{ Clasificación del asma previo al inicio del tratamiento } \\
\hline $\begin{array}{l}\text { Paso } 1 \\
\text { Asma Intermitente }\end{array}$ & $\begin{array}{l}\checkmark \text { Síntomas menos de una vez por semana } \\
\checkmark \text { Exacerbaciones de corta duración } \\
\checkmark \text { Síntomas nocturnos menos de } 2 \text { veces por mes } \\
\checkmark \text { VEF1 o Flujo pico Ž } 80 \% \\
\checkmark \text { Variabilidad del VEF1 o Flujo pico }<20 \%\end{array}$ \\
\hline $\begin{array}{l}\text { Paso } 2 \\
\text { Asma leve persistente }\end{array}$ & $\begin{array}{l}\checkmark \text { Síntomas más de una vez/ semana pero menos de una vez por día } \\
\checkmark \text { Síntomas nocturnos más de } 2 \text { veces/ mes pero menos de una vez/ semana } \\
\checkmark \text { VEF } 1 \text { o Flujo pico Ž } 80 \% \\
\checkmark \text { Variabilidad del VEF1 o Flujo pico } 20-30 \%\end{array}$ \\
\hline $\begin{array}{l}\text { Paso } 3 \\
\text { Asma moderada } \\
\text { persistente }\end{array}$ & $\begin{array}{ll}\checkmark & \text { Síntomas diarios } \\
\checkmark & \text { Las exacerbaciones pueden afectar la actividad diaria y el sueño } \\
\checkmark & \text { Síntomas nocturnos al menos una vez por semana } \\
\checkmark & \text { Uso diario del ß2-agonista } \\
\checkmark & \text { VEF1 o Flujo pico } 60-80 \% \text { del predicho } \\
\checkmark & \text { Variabilidad del VEF1 o Flujo pico Ž30\% }\end{array}$ \\
\hline $\begin{array}{l}\text { Paso } 4 \\
\text { Asma severa } \\
\text { persistente }\end{array}$ & $\begin{array}{l}\checkmark \text { Síntomas diarios continuos } \\
\checkmark \text { Exacerbaciones frecuentes } \\
\checkmark \text { Síntomas nocturnos frecuentes } \\
\checkmark \text { Actividad física limitada } \\
\checkmark \text { VEF1 o Flujo pico Ž } 60 \% \text { del predicho } \\
\checkmark \text { Variabilidad del VEF1 o Flujo pico Ž } 30 \%\end{array}$ \\
\hline
\end{tabular}


Los pacientes durante su régimen de medicación pueden ser reclasificados hacia pasos menores o mayores de acuerdo a la respuesta por lo que los esquemas de tratamiento pueden ser modificados de acuerdo a ello.

Todos los pacientes aunque sean intermitentes hasta los severos persistentes pueden presentar exacerbaciones severas que de no ser reconocidas pueden ser potencialmente fatales. Los factores relacionados con mayores riesgos de mortalidad son: historia previa de crisis que ha amenazado la vida, hospitalización en el año previo, problema psicosocial, historia de intubación por asma, reciente reducción o suspensión de terapia esteroidal y el no-cumplimiento del tratamiento.

\section{Manejo del asma}

Las metas para el manejo exitoso del asma son:

1. Obtener y mantener el control de los síntomas.

2. Prevenir las exacerbaciones.

3. Mantener la función pulmonar cerca de los valores normales (cuando sea posible).

4. Mantener niveles normales de actividad, incluyendo ejercicio.

5. Evitar los efectos adversos de los medicamentos.

6. Prevenir el desarrollo de limitación al flujo aéreo irreversible.

7. Prevenir la mortalidad por asma.

El tratamiento del asma tiene seis partes correlacionadas entre sí, que son:

1. Educar a los pacientes para que tomen parte activa en el manejo de su enfermedad.

2. Asesorar y monitorear la severidad del asma con el reporte de síntomas y medición de la función pulmonar (Flujo pico).

3. Evitar la exposición a factores de riesgo.

4. Establecer individualmente los planes de medicación en el control a largo plazo de pacientes pediátricos y adultos.

5. Establecer planes individuales para el manejo de las exacerbaciones.

6. Dar seguimiento regular a cada caso.

\section{EDUCACION:}

Debe ser un proceso continuo. El paciente y su familia deben recibir información sencilla y entrenamiento para que el paciente pueda tener cambios positivos en el control de la enfermedad, saber ajustar la medicación cuando lo necesite de acuerdo al plan dado por el personal de salud y mantener una buena calidad de vida. El énfasis se debe hacer en una adecuada integración entre el personal de salud, el paciente y la familia del paciente.

\section{Asesorar y monitorear la severidad del asma con el reporte de síntomas y medición de la función pulmonar:}

La severidad del asma puede ser estimada midiendo los síntomas, la función pulmonar y los requerimientos de medicación.

Los cuestionarios estructurados no han logrado ser validados sobre otras medidas objetivas de la severidad del asma, pero son sensibles para detectar el deterioro del asma. Las preguntas específicas y particularmente importantes en la evaluación de la respuesta a tratamiento son: ¿Con qué frecuencia usa los medicamentos de alivio rápido?, ¿Con qué frecuencia experimenta síntomas nocturnos como tos, respiración sibilante o disnea?. Puede ayudar también el interrogar al paciente sobre la limitación de la actividad diaria.

Los estudios de función pulmonar son esenciales para el diagnóstico y para asesorar la severidad del asma en pacientes mayores de 5 años. Esto nos da una medida indirecta de la hiperreactividad de la vía aérea la cual puede correlacionarse con el grado de inflamación. Además para monitorear el curso de la enfermedad y la respuesta del paciente al tratamiento.

La medición del Flujo pico es importante para el monitoreo en el consultorio, consulta externa, urgencias, en los salones del hospital y en la casa. Sirve para evaluar la severidad, el grado de variación diurna de la función pulmonar, monitorear la respuesta al tratamiento durante la crisis, detectar el deterioro asintomático de la función pulmonar en la casa u oficina permitiendo la intervención temprana, monitorear la respuesta al tratamiento crónico, proveer justificación objetiva de tratamiento para el paciente, e identificar desencadenantes como los sensibilizantes ocupacionales. Está recomendado su uso en:

- $\quad$ Las oficinas del personal de salud involucrado.

- Durante las exacerbaciones agudas en el consultorio o en el departamento de urgencias.

- A largo plazo para los pacientes que han requerido hospitalización.

- Para los pacientes que no son capaces de percibir la disminución en el flujo aéreo de manera adecuada.

\section{Evitar la exposición a factores de riesgo:}

A pesar de que la intervención farmacológica para tratar el asma ya establecida es muy efectiva para controlar los síntomas y mejorar la calidad de vida, se debe poner especial 
atención a las medidas de prevención de esta enfermedad crónica. El asma puede ser desencadenada por una variedad de factores de riesgo que incluyen alergenos, contaminación ambiental, comidas, medicamentos y otros.

\section{Prevención primaria:}

La prevención primaria no ha sido posible en esta enfermedad, la evidencia indica que la sensibilización alérgica es el precursor más común para el desarrollo de asma, pero ésta puede ocurrir incluso antes de nacer, y no hay medidas prenatales recomendadas a este momento. La prescripción de dietas que eviten antígenos en las mujeres de alto riesgo que dan de mamar reduce sustancialmente el eczema atópico pero se necesitan mejores estudios (Evidencia C). Los niños de madres fumadoras tienen 4 veces más posibilidad de desarrollar una enfermedad sibilante en su primer año de vida. Pero existe poca evidencia (en meta-análisis) de que el fumado de la madre durante el embarazo tenga efecto sobre la sensibilización alérgica. Pero sí existe evidencia de que el tabaquismo durante el embarazo causa problemas en el desarrollo del pulmón y aumenta la frecuencia de enfermedad sibilante no alérgica en la infancia. Por esto se concluye que la exposición al humo de tabaco tanto prenatal como postnatal tiene una influencia negativa sobre la enfermedad sibilante (Evidencia A).

\section{Prevención secundaria:}

Hay dos estudios que sugieren que el uso de antihistamínicos H1 pueden prevenir la aparición de sibilancias en niños que se presentan inicialmente con dermatitis atópica pero necesitan confirmación. El uso de inmunoterapia como prevención está en estudio.

\section{Prevención terciaria:}

Se sugiere evitar la exposición a los factores desencadenantes para mejorar el control del asma y disminuir la necesidad de tratamientos. Entre estos:

1. Evitar los alérgenos dentro de la casa como ácaros, alergenos de animales, alérgenos de la cucaracha y hongos.

2. Evitar los alérgenos en el medio ambiente externo como polen y moho.

3. Evitar los contaminantes del aire internos como el humo de tabaco (pasivo o activo). A los parientes de niños con asma se les debe pedir que no fumen o se abstengan de hacerlo en las habitaciones del niño y por supuesto los pacientes con asma no deben fumar (Evidencia B).

4. Evitar los contaminantes ambientales como ozono, óxido nítrico, aerosoles ácidos y otras partículas.

5. Evitar las exposiciones ocupacionales. La identificación temprana de los sensibilizadores ocupacionales y el remover lo más pronto posible a los pacientes sensibilizados de cualquier futura exposición son aspectos muy importantes en el manejo del asma ocupacional (Evidencia B).

6. Evitar sensibilizantes alimentarios como los sulfitos u otras sustancias que se pruebe provoquen la crisis.

7. Evitar ciertos medicamentos, la aspirina y anti-inflamatorios no esteroidales en pacientes sensibles. No utilizar beta bloqueadores orales o en gotas oftálmicas en ningún paciente asmático.

8. Vacunación para influenza: No se ha establecido el riesgo/ beneficio en los pacientes con asma.

\section{Establecer planes de tratamiento para el manejo a largo plazo:}

Los medicamentos usados son para revertir la inflamación, prevenir síntomas y tratar la obstrucción del flujo aéreo los cuales se clasifican en medicamentos de control "controladores” y medicamentos de alivio rápido.

La ruta de administración preferida es la inhalada, ya que pueden ser dadas altas dosis en la vía aérea directamente con la ventaja de mínimos efectos secundarios o sin ellos, además de que el inicio de acción es más rápido.

El uso y la técnica de inhalación deben ser revisadas con frecuencia. El uso de espaciador mejora la entrega del medicamento desde un inhalador de dosis medida (Evidencia A). Los espaciadores disminuyen el depósito del medicamento en boca y orofaringe, disminuye la tos y la candidiasis oral cuando se usa inhaladores de glucococorticoides (Evidencia A). Además disminuye la biodisponibilidad de los glucocorticoides en cuanto a efectos sistémicos se refiere (Evidencia B). La utilización de beta dos agonistas a altas dosis con espaciador en la crisis es equivalente al medicamento nebulizado, teniendo mejores resultados en niños que en adultos (Evidencia B).

Lo ideal es un esquema de tratamiento por medio de un Abordaje por pasos que permite lograr y mantener el control de la enfermedad.

1. El buen control del asma es definido como:

2. Síntomas crónicos mínimos o ausentes, incluyendo las molestias nocturnas.

3. Exacerbaciones mínimas o ausentes.

4. No necesidad de acudir al servicio de Urgencias.

5. Mínimo (idealmente no) uso de beta dos agonistas cuando es necesario (PRN).

6. Sin limitación en la actividad, incluyendo ejercicio.

7. Variabilidad del flujo pico de menos del $20 \%$.

8. Flujo pico normal o cerca de lo normal.

9. Mínimos (o no) efectos secundarios de los medicamentos. 


\section{Escogencia del tratamiento}

Se debe hacer de acuerdo a la severidad del asma, el tratamiento actual del paciente, las propiedades farmacológicas, la disponibilidad del tratamiento y de los costos del mismo.

Como el asma es una enfermedad dinámica y una enfermedad crónica los planes de tratamiento deben de acomodarse a esa variabilidad e individualmente en el tiempo.

Un aspecto esencial de todo esquema de tratamiento es que debe ser monitoreado el efecto del tratamiento (incluyendo cumplimiento, efecto en la función pulmonar y síntomas) y adaptar el tratamiento a la variabilidad del asma. El abordaje terapéutico según severidad permite esta flexibilidad.

Un abordaje apropiado recomienda que el tipo (número), dosis y frecuencia de los medicamentos deben aumentar con relación a la severidad del asma. Lo ideal es alcanzar las metas del tratamiento con la mínima medicación posible. En el desarrollo de un plan por parte del personal de salud, el médico puede considerar dar el máximo tratamiento al inicio con ciclo un corto de glucocorticoides y/o dosis máximas de glucocorticoides inhalados más agonistas beta dos de acción prolongada (Evidencia D) para tener el control del asma del paciente lo más pronto posible y luego disminuir el tratamiento; ó iniciar el tratamiento según severidad y aumentarlo gradualmente si es necesario. Cuando se mantiene el control por 3 meses, se debe considerar una reducción del tratamiento a un paso inferior. Esta reducción se necesita para identificar el mínimo tratamiento requerido para mantener el control. Cuando el control no se logra o se pierde, se debe subir al siguiente paso y se debe estar seguro de que el paciente está usando adecuadamente el tratamiento.

\section{Paso 1. Asma intermitente:}

Se recomienda el uso de beta dos agonistas de acción corta, cuando sea necesario (Evidencia A). Pero los pacientes con asma intermitente con exacerbaciones severas deben ser tratados como si tuvieran asma persistente moderada (Evidencia D).

El tratamiento incluye medicación previo al ejercicio cuando sea necesario, es preferible el uso de los beta dos agonistas de acción rápida, existen otras alternativas como: las cromonas o modificadores de leucotrienos (Evidencia B), o tratamiento previo a la exposición de un alergeno, siendo de elección las cromonas (Evidencia B).

Pueden ser utilizados otros medicamentos para alivio rápido como anticolinérgico inhalado o beta dos agonista de acción corta vía oral, pero estos tienen un inicio de acción más lento y/o mayor riesgo de efectos secundarios (Evidencia A). Ocasionalmente, una crisis más prolongada o severa requiere de un ciclo corto de glucocorticoides vía oral.

\section{Paso 2. Asma persistente leve:}

Requiere de medicamentos controladores a diario para obtener y mantener el control del asma. La terapéutica primaria es el uso diario de tratamiento antiinflamatorio y los preferidos son los glucocorticoides inhalados (Evidencia A). La dosis inicial sugerida es 200-500 ugr/día de dipropionato de Beclometasona ó Budesonida, ó 100-250 ugr/día de Fluticasona o equivalente dividido en 1 o 2 dosis/día (Evidencia B). Ver tabla de equivalencia en apéndice 1.

Otras alternativas son: teofilina de acción prolongada, cromonas y modificadores de leucotrienos; pero son menos efectivas que los glucocorticoides inhalados o solo sirven en cierto grupo de pacientes que no pueden ser identificados sin la prueba terapéutica (Evidencia A). Si el paciente no mejora en 4 semanas los glucocorticoides inhalados deben ser iniciados. La efectividad de estos tratamientos necesita de estudios a largo plazo.

Además estos pacientes deben usar beta dos agonistas de acción rápida en caso necesario, pero no más de 3 o 4 veces al día.

\section{Paso 3. Asma persistente moderada:}

Requiere de medicamentos controladores a diario para obtener y mantener el control del asma. El tratamiento controlador preferido es una combinación de glucocorticoides inhalados (200-1000 mgr de dipropionato de Beclometasona, 4001000 ugr de Budesonida o 250-500 ugr de Fluticasona) divididos en 1 o 2 dosis/día y beta dos agonistas de acción prolongada dos veces al día (Evidencia A).

Otros medicamentos alternativos que se pueden agregar al esteroide inhalado en orden de costo son:

- Teofilina de acción prolongada. Menos efectiva pero más barata. Se recomienda mantener niveles entre 5-15 $\mu \mathrm{gr} / \mathrm{ml}$.

- Beta dos agonista de acción prolongada oral. Puede ser tan efectivo como los inhalados pero los efectos secundarios son mayores.

- Modificador de leucotrienos.

Además requiere de beta dos agonistas de acción corta para mejor los síntomas cuando sea necesario pero no más de 3 o 4 veces al día.

\section{Paso 4. Asma persistente severa:}

Generalmente el control del asma se logra obtener si se toman los parámetros mencionados. La meta del tratamiento es alcanzar los mejores resultados posibles (menos síntomas, el mínimo uso de beta dos agonistas de acción corta, el mejor flujo pico con la menor variabilidad y la menor cantidad de efectos secundarios posibles).

El tratamiento requiere múltiples medicamentos controladores. El tratamiento primario incluye glucocorticoides 
inhalados a dosis altas (más de 1000mgr. de dipropionato de beclometasona o equivalentes) más beta dos agonista de acción prolongada inhalado dos veces al día (Evidencia A). Mejor resultado se obtiene si la dosis total de glucocorticoide inhalado se fracciona y se administra 4 veces al día (Evidencia A).

Como alternativas para el beta dos agonista de acción prolongada se tiene la teofilina de acción prolongada, modificadores de leucotrienos y beta dos agonistas de acción prolongada orales (Evidencia B). Todos estos pueden ser agregados al esquema primario si se requirieran.

Los beta dos agonistas de acción corta deben ser usados tanto como sea necesario.
Si se necesita de glucocorticoides orales por largo tiempo deben ser usados a la mínima dosis posible y en una sola dosis diaria para minimizar los efectos secundarios.

Si el paciente requiere de esteroides orales y presenta efectos secundarios, se debe evaluar la posibilidad de utilizar metotrexate, ciclosporina A o sales de oro para disminuir los efectos secundarios (Evidencia B). (Solamente por el especialista)

La complejidad de múltiples tratamientos diarios es un factor de no-adherencia lo que complica el manejo de estos pacientes, por lo cual ellos requieren de educación exhaustiva y de manejo de soporte.

\section{Medicación recomendada según nivel de severidad en adultos}

En todos los pasos: en adición a la dosis regular de la terapia, pueden ser utilizados los ß2- agonista* de acción corta para el alivio de los síntomas, pero no debe ser más de 3-4 veces al día

\begin{tabular}{|c|c|c|}
\hline Grado de severidad & Medicación diaria & Otras opciones terapéuticas ${ }^{\star \star}$ \\
\hline $\begin{array}{l}\text { Paso } 1 \\
\text { Intermitente }\end{array}$ & No es necesario & \\
\hline $\begin{array}{l}\text { Paso } 2 \\
\text { Leve persistente }\end{array}$ & $\begin{array}{l}\checkmark \text { Glucocorticoide inhalado } \\
\text { (Ž500 } \mathrm{gg} \text { Beclometasona o su equivalente) }\end{array}$ & $\begin{array}{l}\checkmark \text { Teofilina de liberación lenta, o } \\
\checkmark \text { Cromonas, o } \\
\checkmark \text { Modificadores de leucotrienos }\end{array}$ \\
\hline $\begin{array}{l}\text { Paso } 3 \\
\text { Moderado persistente }\end{array}$ & $\begin{array}{l}\checkmark \text { Glucocorticoide inhalado } \\
\text { (200-1000 } \mu \text { g Beclometasona o su } \\
\text { equivalente) }+ \text { ß2-agonista de acción } \\
\text { prolongada } \$\end{array}$ & 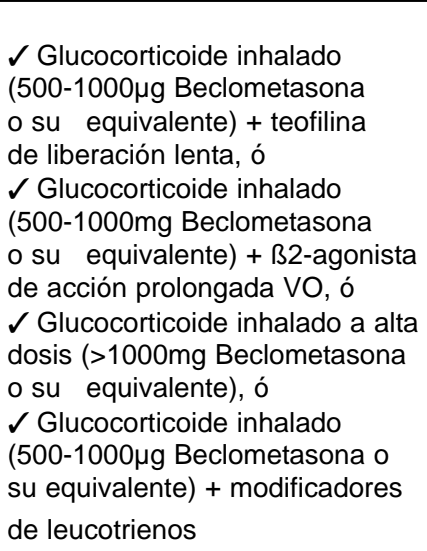 \\
\hline $\begin{array}{l}\text { Paso } 4 \\
\text { Severo persistente }\end{array}$ & $\begin{array}{l}\checkmark \text { Glucocorticoide inhalado } \\
\text { (>1000mg Beclometasona o su } \\
\text { equivalente) + } \text { ß2-agonista de acción }_{\text {prolongada } \$ \text { uno o más de las }} \\
\text { siguientes opciones si lo requiriera: } \\
\text { - Teofilina de liberación lenta } \\
\text { - Modificadores de leucotrienos } \\
\text { - B2-agonista de acción prolongada por vía oral } \\
\text { - Glucocorticoide VO }\end{array}$ & \\
\hline
\end{tabular}

- Se utilizará un beta agonista de acción corta como tratamiento para alivio rápido, que en los pasos 1 , 2 y 3 no debería excederse de 3-4 veces al día a menos que esté en crisis.

- Para todos los pasos: una vez que el asma esté controlada debe mantenerse el tratamiento al menos 3 meses para luego hacer una reducción del mismo tratando de mantener la mínima medicación requerida

* Otras opciones como tratamiento de rescate o de alivio son: (en orden ascendente de costo) anticolinérgicos inhalados, ß2agonista de acción corta por vía oral y teofilina de acción corta. ${ }^{* * E l}$ orden está en relación ascendente del costo

*** Los asmáticos intermitentes con exacerbaciones severas deben ser tratados como si fueran moderados persistentes (Evidencia D)

$\S \quad$ Hasta que exista la disponibilidad en la C.C.S.S. del Beta 2 agonista inhalado de acción prolongada puede utilizarse los de acción corta a dosis fija. 


\section{Medicación recomendada según nivel de severidad en niños}

En todos los pasos: en adición a la dosis regular de la terapia, pueden ser utilizados los $\beta_{2}$ - agonista ${ }^{*}$ de acción corta para el alivio de los síntomas, pero no debe ser más de 3-4 veces al día

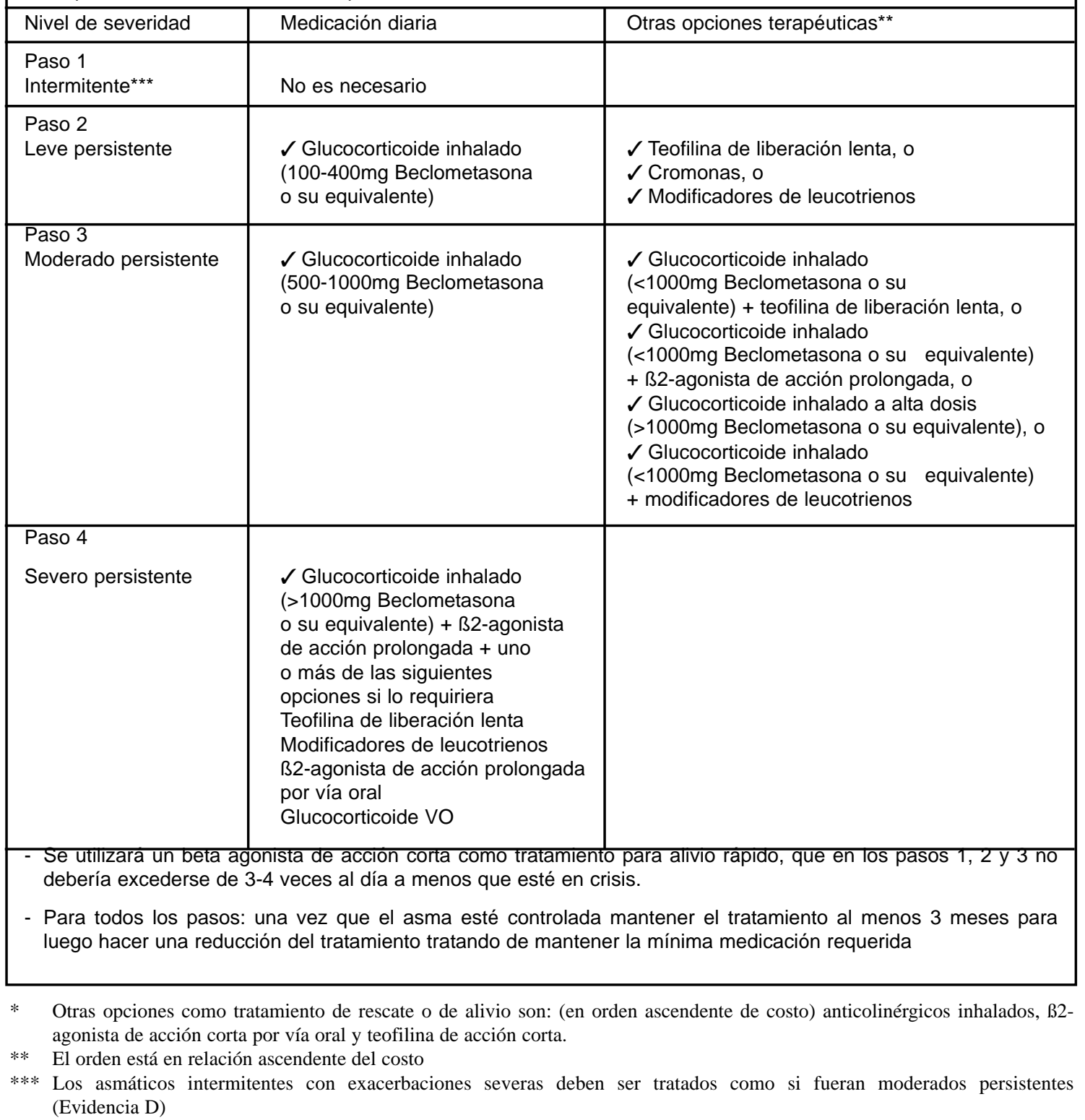

\section{Establecer planes de manejo de las exacerbaciones:}

La terapia primaria para las exacerbaciones es: la administración repetitiva de beta dos agonista de acción corta, bromuro de Ipratropium, la introducción temprana de glucocorticoides sistémicos y el suplemento de oxígeno.

Las prioridades del tratamiento son revertir la obstrucción de la vía aérea y corregir la hipoxemia tan pronto como sea posible y el plan para la prevención de las futuras recaídas. Es crucial para el éxito del tratamiento el monitoreo de la condición del paciente y la respuesta al tratamiento con la medición seriada de la función pulmonar y la oximetría.
La recuperación de la crisis de asma es gradual; toma días para que la función pulmonar regrese a lo normal y semanas para que la hiperreactividad disminuya. Los síntomas y los datos de examen físico no son buenos indicadores de la limitación del flujo aéreo. El tratamiento debe continuar siendo intensivo hasta lograr que el flujo pico o el VEF1 esté cerca de lo normal o al mejor valor de cada paciente.

\section{Manejo de las exacerbaciones en casa:}

Este dependerá de la existencia de un plan de manejo escrito donde se tomará en cuenta la experiencia del paciente y de sus familiares en el inicio del tratamiento para la crisis en casa. Este plan debe ser claro en: 
- ¿Cómo reconocer los signos de deterioro?

- Modificaciones a realizar en el tratamiento

- Medir la severidad de la crisis

- ¿Cuándo es apropiado buscar tratamiento más especializado?.
Los pacientes deben saber reconocer el deterioro de su enfermedad idealmente con el uso del flujo pico (Flujo pico $<80 \%$ del mejor personal o del predicho en 2 días sucesivos ó un Flujo pico $>70 \%$ que no mejora con el uso del broncodilatador) ó con los datos clínicos (tos, disnea, respiración sibilante, uso de músculos accesorios y retracción supraesternal).

El manejo de la crisis debe basarse en el grado de severidad de la misma basándose en el siguiente cuadro:

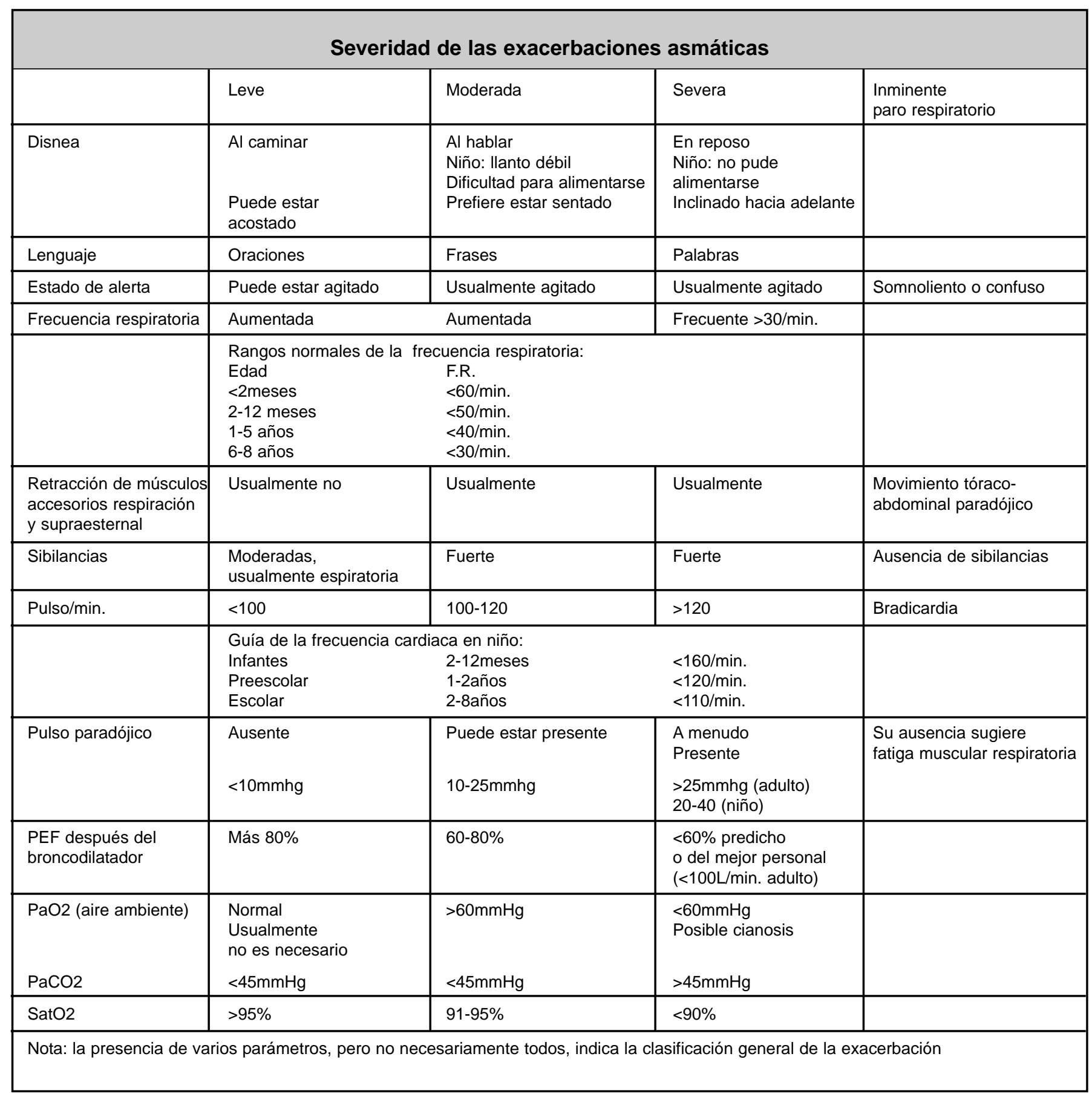




\section{l) Broncodilatadores:}

Para las exacerbaciones moderadas la administración repetida de beta dos agonista de acción rápida (2-4 inhalaciones cada 20 minutos durante la primera hora) es usualmente lo mejor y el método más rápido para revertir la obstrucción al flujo aéreo.

Luego de la primera hora, la dosis de beta dos agonista requerida depende de la severidad de la exacerbación:
Leve: 2-4 inhalaciones cada 3-4 horas

Moderada: 6-10 inhalaciones cada 1-2 horas

Severa: más de 10 inhalaciones (con espaciador) o una dosis con nebulizador al menos cada hora.

No se necesita otro tipo de medicación si con el beta dos agonista se obtiene una respuesta Completa (Flujo pico $>80 \%$ del predicho o del mejor personal y la respuesta se mantiene al menos por 3-4 horas)

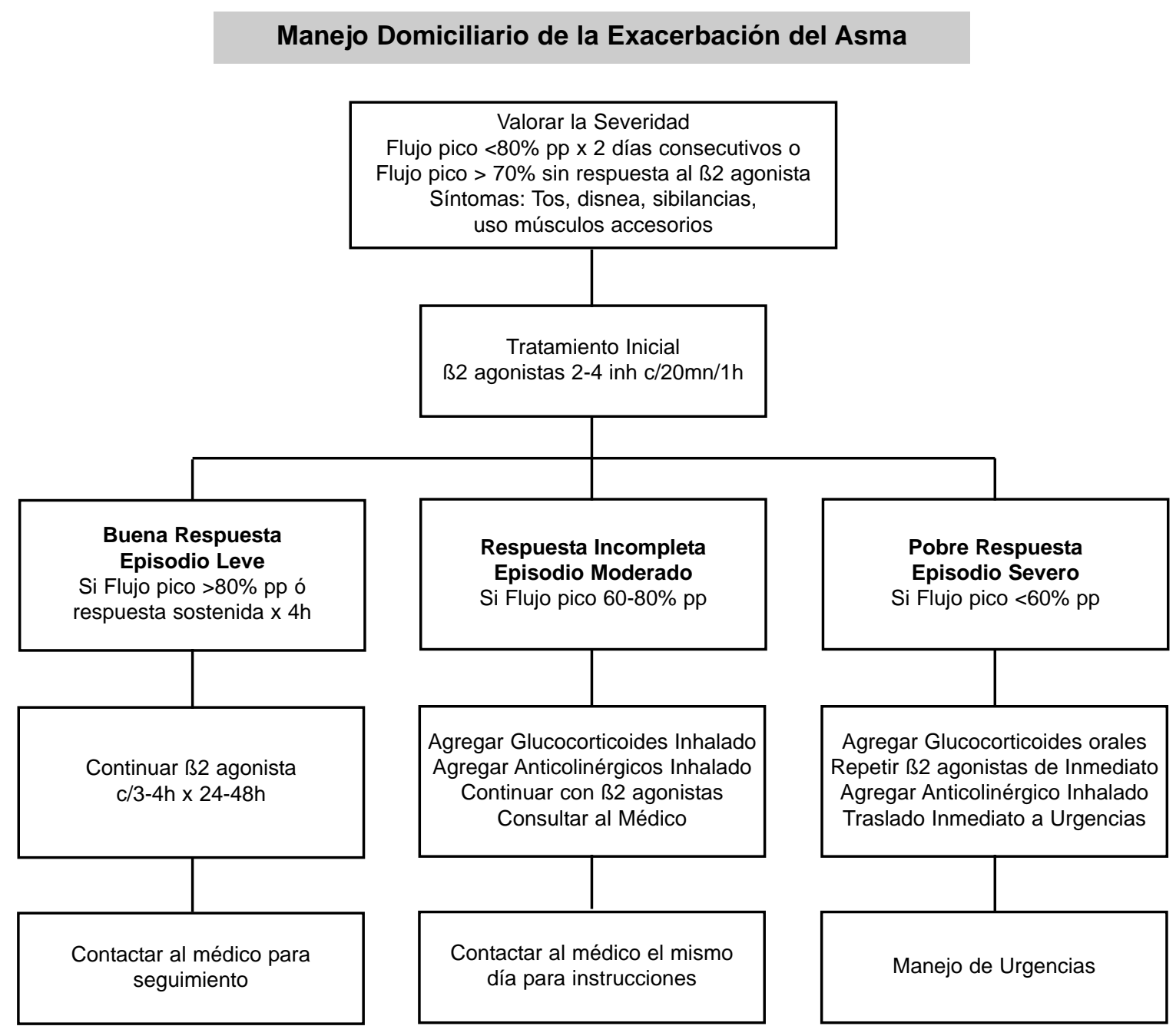

$\mathrm{pp}=$ predicho para el paciente o mejor personal 


\section{2) Glucocorticoides:}

Estudios indican beneficio si el plan de acción incluye aumentar los glucocorticoides inhalados tempranamente en la crisis; pero los datos de utilidad de esta estrategia son limitados.

Los glucocorticoides orales $(0.5-1 \mathrm{mgr} / \mathrm{kg}$ de prednisolona o su equivalente durante un período de 24 horas) deben ser usados para la rápida resolución de todas las exacerbaciones leves. Una guía para saber si es necesario el uso de glucocorticoides orales es si la respuesta a los beta dos agonistas de acción rápida no es pronta o sostenida (Flujo pico $>80 \%$ del predicho o del mejor personal) luego de 1 hora.

\section{Tratamiento adicional}

Si hay mejoría sostenida del Flujo pico y los síntomas, el manejo puede continuar en casa bajo supervisión. La recuperación total de la crisis es gradual y los medicamentos para la crisis deben ser continuados por muchos días para sostener el alivio de los síntomas y mantener la mejoría del Flujo pico.

Pero no debe haber atraso en buscar ayuda médica en los siguientes casos:

- Si el paciente pertenece al grupo de alto riesgo de muerte por asma.

- Si la exacerbación es severa (por ejemplo si el Flujo pico se mantiene en menos del $60 \%$ del predicho o del mejor personal luego de tratamiento con beta dos agonistas de acción corta).

- Si la respuesta a broncodilatador no es rápida y sostenida por al menos 3 horas.

- Si no hay mejoría 2-6 horas después del inicio de glucocorticoides.

- Si existe deterioro progresivo.

* El beta 2 agonista inhalado debe ser administrado simultáneamente con el anticolinérgico (Bromuro de Ipratropium)

\section{Manejo de las exacerbaciones en el hospital}

Las crisis severas de asma son reales emergencias médicas y deben ser manejadas en el hospital o en el servicio de urgencias. (Ver tabla de severidad de las exacerbaciones asmáticas)

Luego de la valoración de la severidad de la crisis, se debe iniciar de inmediato con el tratamiento que incluye:

\section{Oxígeno}

Se debe administrar oxígeno por cánula nasal o mascarilla para obtener una saturación de oxígeno Ž a 90\% en adultos y Ž 95\% en niños. Si no se puede medir la saturación se debe administrar oxígeno a todos los pacientes en crisis. Se han descrito problemas de acidosis respiratoria en pacientes con obstrucción muy severa y que recibieron 100\% de oxígeno; entonces ahora se recomienda el uso de oximetría para la administración de oxígeno de una manera segura (Evidencia D). (Si se pudiera se recomienda la nebulización con oxígeno en lugar de aire)

\section{Beta Dos agonistas de acción rápida}

Aunque generalmente son administrados por nebulización se obtiene una broncodilatación equivalente, más rápido inicio, menos efectos secundarios y menos tiempo en el servicio de urgencias si se utiliza un inhalador dosis medida con espaciador (Evidencia A).

Tres estudios controlados y randomizados han mostrado que la terapia continua es más efectiva que la intermitente, especialmente para los que tienen una exacerbación más severa, obteniendo mejores Flujo pico y menos tasas de internamiento.

El uso de estos por vía intravenosa se indica cuando la respuesta es mala a altas dosis de la medicación nebulizada; sin embargo los datos son confusos sobre la utilidad de este tratamiento.

\section{Epinefrina}

Esta indicada en el tratamiento de las reacciones anafilácticas y del angioedema. Se pueden usar en las crisis severas de asma cuando no hay disponibilidad del beta dos agonistas de acción corta; pero la posibilidad de efectos adversos es grande principalmente en los pacientes hipóxicos. Algunas veces es considerada en los pacientes con crisis severa de asma que no responde a beta dos agonista de acción rápida, pero lo mejor sería agregar un beta dos agonista intravenoso (Evidencia B).

\section{Otros broncodilatadores}

Bromuro de Ipratropium: La combinación de beta dos agonista nebulizado con este anticolinérgico puede producir mejor brondilatación que con solo uno de ellos (Evidencia B) debería ser considerado antes de agregar las metilxantinas. Algunos estudios reportan que con la combinación de estos medicamentos las tasas de hospitalización disminuyen (Evidencia A) y mayor mejoría en el Flujo pico y VEF1 (Evidencia B).

Metilxantinas: Tienen un efecto broncodilatador equivalente a los beta dos agonistas, pero por los efectos secundarios solo deben ser consideradas una terapia alternativa.

\section{Glucocorticoides sistémicos}

Aceleran la resolución de las exacerbaciones y deben ser considerados parte integral del manejo de todas las crisis (Evidencia A), especialmente si:

- El beta dos agonista inhalado inicial ha fallado para obtener la mejoría esperada. 
- En caso de exacerbación en el paciente que toma glucocorticoides orales.

- Crisis previas que han requerido glucocorticoides orales.

La vía oral es tan efectiva como la intravenosa y se prefiere por ser menos invasiva y menos costosa; excepto en pacientes con vómitos o problemas para la absorción del medicamento.

Los glucocorticoides sistémicos requieren al menos de 4 horas para producir mejoría clínica. Un meta-análisis mostró que las dosis de los glucocorticoides sistémicos equivalentes a $60-80 \mathrm{mg}$ de metilprednisolona o 300-400mg de hidrocortisona son dosis adecuadas para los pacientes hospitalizados (Evidencia B). No hay datos convincentes sobre la duración adecuada del tratamiento con prednisolona oral, pero se considera en adultos 10-14 días y en niños de 3-5 días (Evidencia D). Hay evidencia de que no hay beneficio en disminuir gradualmente la dosis de prednisolona oral en corto plazo o en período de semanas (Evidencia B).

\section{Glucocorticoides inhalados}

El óptimo aumento de estos para prevenir las exacerbaciones de asma no ha sido bien definido. Las guías internacionales recomendaban doblar la dosis pero no existe evidencia para dar soporte a esta recomendación.

Altas dosis pueden ser apropiadas. Un estudio mostró que la combinación de altas dosis de glucocorticoides y salbutamol en asma aguda produjo mejor broncodilatación que el salbutamol solo (Evidencia B). Además los glucocorticoides inhalados son tan efectivos como los orales para prevenir recaídas. Pacientes que egresan del servicio de urgencias con prednisolona y budesonida tuvieron menos cantidad de recaídas que los que usaron solo prednisona (Evidencia B). Una dosis alta de glucocorticoides inhalados (2400mg/día de budesonida dividida en 4 dosis) tuvo una cantidad similar de recaídas que con $40 \mathrm{mg}$ /día de prednisolona vía oral (Evidencia A); como el costo es importante se debe considerar para los pacientes que no toleran o no están dispuestos a tomar la prednisolona vía oral.

\section{Magnesio}

La evidencia presente sugiere que el uso intravenoso de magnesio no se debe usar de rutina en las exacerbaciones de asma pero puede reducir la tasa de hospitalización de un selecto grupo de pacientes: adultos que se presentan con VEF1 25-30\% del predicho (Evidencia B). La dosis intravenosa es única y de 2 gr en infusión durante 20 minutos.

\section{Otros tratamientos}

Antibióticos: No es de uso rutinario excepto cuando hay neumonía, esputo purulento que sugiera infección bacteriana o si se sospecha sinusitis.
Mucolíticos nebulizados: No han probado beneficio.

Sedación: Nunca durante las crisis de asma se debe dar depresores respiratorios como ansiolíticos y drogas hipnóticas.

Antihistamínicos y terapia física: No han mostrado efectividad en el tratamiento de las crisis.

\section{Criterios para monitoreo contínuos}

Estos incluyen:

1. Respuesta inadecuada o deterioro con 1-2 horas de tratamiento.

2. Obstrucción severa persistente (Flujo pico $<30 \%$ del predicho o del mejor personal).

3. Historia pasada de asma severa, particularmente si ha requerido hospitalización o UCI.

4. Presencia de factores de riesgo para muerte por asma.

5. Síntomas prolongados antes de la consulta en urgencias.

6. Acceso inadecuado desde la casa al hospital o a los medicamentos.

7. Malas condiciones en el hogar.

8. Dificultad para transportarse al hospital si hay deterioro.

\section{Criterios para egresar del servicio de urgencias vs hospitalización:}

1. Pacientes con un VEF1 o Flujo pico antes del tratamiento por debajo del $25 \%$ del predicho o del mejor personal o con VEF1 o Flujo pico por debajo del $40 \%$ del predicho o mejor personal usualmente requieren hospitalización.

2. Pacientes con función pulmonar postratamiento de 40$60 \%$ del predicho pueden ser potencialmente egresables si las condiciones de seguimiento en la comunidad y el cumplimiento del tratamiento es seguro.

3. Pacientes con evidencia objetiva de función pulmonar igual o mayor al $60 \%$ del predicho usualmente son egresables.

\section{Criterios para la admisión a la UCI:}

Está indicado en los pacientes que cumplen con uno de los siguientes:

1. Asma severa con mala respuesta al tratamiento inicial en el departamento de urgencias y que empeoran a pesar de este.

2. Presencia de confusión u otros signos de falla respiratoria inminente o pérdida de la conciencia. (Ver tabla de severidad de exacerbaciones asmáticas) 
3. Datos de probable falla respiratoria: hipoxemia a pesar de oxígeno suplementario (paO2 $<60 \mathrm{mmHg}$ y/o paCO2>45 mmHg en adultos, o saturación por oximetría < $90 \%$ en niños).

\section{Egreso del servicio de urgencias:}

Al egresar a un paciente se debe:

1. Debe recibir mínimo de 7-10 días de prednisona y continuar con los broncodilatadores.

2. La dosis del broncodilatador debe ser gradualmente disminuida basado en los síntomas y la mejoría objetiva hasta su dosis de mantenimiento usual previo a la crisis.

3. El bromuro de ipratropium no da beneficio luego de la fase aguda y puede ser rápidamente descontinuado.

4. El paciente debe de continuar o iniciar el uso de glucocorticoides inhalados.

5. Durante la fase de recuperación el paciente debe descontinuar el uso de beta dos agonistas de acción prolongada hasta que esté estable de nuevo.

6. La técnica de inhalación y el uso de flujo pico debe ser revisada.

7. Los factores desencadenantes que precipitaron la crisis deben ser identificados y evitados.

8. Se debe revisar el plan de tratamiento.

9. El uso de glucocorticoides inhalados durante el inicio de la crisis debe ser revisado y readecuado.

10. Se debe instruir al paciente y los familiares para que consulten con su médico en las 24 horas posteriores al egreso, y cuando sea necesario referir al paciente al especialista.

\section{Criterios de egreso luego de hospitalización:}

No hay criterios absolutos, pero se debe mantener previo al egreso el tratamiento que tendrá en su casa por 12-24 horas, asegurándose así el control de los síntomas con el mismo.

Generalmente los siguientes criterios se deben alcanzar para el egreso:

1. Los beta dos agonistas de acción rápida no se deben de necesitar más de cada 3-4 horas.

2. Saturación por oximetría $>90 \%$ respirando aire ambiente.

3. El paciente camina confortablemente.

4. El paciente no se despierta durante la noche o temprano en la mañana con necesidad de dosis adicionales del broncodilatador.
- Examen físico normal o cerca de lo normal.

- VEF1 o Flujo pico $>70 \%$ del predicho o del mejor personal luego de beta dos agonistas de acción corta inhalados.

- El paciente es capaz de usar los inhaladores correctamente.

\section{Dar seguimiento regular:}

Los pacientes con asma requieren de un seguimiento regular y apoyo por los profesionales en salud acerca de su condición. El monitoreo continuo es necesario para asegurar que las metas han sido logradas.

Para que el paciente logre el control del asma requiere consultas para revisar el uso del flujo pico y los síntomas, la técnica en el uso de los medicamentos inhalados, factores de riesgo y métodos para controlarlos.

Se recomienda consulta con el especialista cuando:

1. El paciente ha tenido una crisis y tiene poca habilidad para su propio manejo o tiene una familia que no coopera.

2. Los signos y síntomas son atípicos y existen problemas con diagnóstico diferencial.

3. Existen entidades que complican el asma como sinusitis, pólipos nasales, aspergilosis o rinitis severa.

4. Necesidad de exámenes complementarios.

5. Paciente no responde adecuadamente a la terapia para el asma.

6. Pacientes con asma persistente moderada o severa.

7. El paciente requiere de guías para el control de su medio ambiente, cese de fumado, complicaciones del tratamiento o dificultad para el cumplimiento.

Una vez establecido el control las visitas pueden ser cada 1-6 meses y según la evolución del mismo. 


\section{Manejo Hospitalario de las Exacerbaciones de Asma}

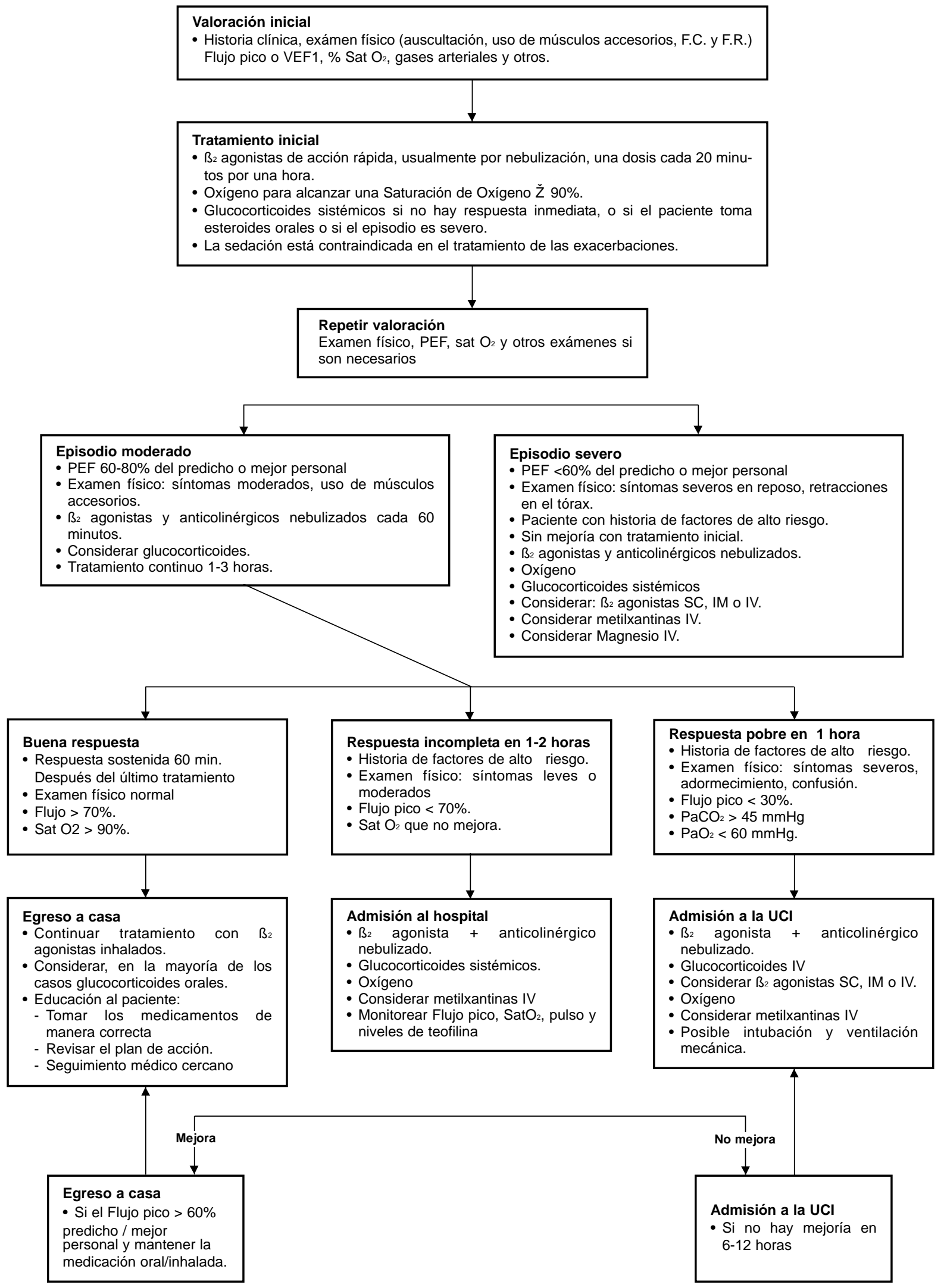

(*) Tomado de Global Strategy for Asthma Management and Prevention. Revisión 2002. 


\begin{tabular}{|c|c|c|c|}
\hline \multicolumn{4}{|c|}{$\begin{array}{c}\text { Apéndice No. } 1 \\
\text { Dosis estimadas equipotente de los glucocorticoides inhalados }\end{array}$} \\
\hline \multicolumn{4}{|l|}{ Adultos } \\
\hline Medicamento & Dosis baja & Dosis media & Dosis alta \\
\hline \multicolumn{4}{|l|}{ Dipropionato de } \\
\hline Beclometasona & $200-500 \mu \mathrm{g}$ & $500-1000 \mu \mathrm{g}$ & $>1000 \mu \mathrm{g}$ \\
\hline Budesonida & $200-400 \mu \mathrm{g}$ & $400-800 \mu \mathrm{g}$ & $>800 \mu \mathrm{g}$ \\
\hline Fluticasona & $100-250 \mu \mathrm{g}$ & $250-500 \mu \mathrm{g}$ & $>500 \mu \mathrm{g}$ \\
\hline Acetato de triamcinolona & $400-1000 \mu \mathrm{g}$ & $1000-2000 \mu \mathrm{g}$ & $>2000 \mu \mathrm{g}$ \\
\hline \multicolumn{4}{|l|}{ Niños } \\
\hline Medicamento & Dosis baja & Dosis media & Dosis alta \\
\hline \multicolumn{4}{|l|}{ Dipropionato de } \\
\hline Beclometasona & $100-400 \mu \mathrm{g}$ & $400-800 \mu \mathrm{g}$ & $>800 \mu \mathrm{g}$ \\
\hline Budesonida & $100-200 \mu \mathrm{g}$ & $200-400 \mu \mathrm{g}$ & $>400 \mu \mathrm{g}$ \\
\hline Fluticasona & $100-200 \mu \mathrm{g}$ & $200-500 \mu \mathrm{g}$ & $>500 \mu \mathrm{g}$ \\
\hline Acetato de triamcinolona & $400-800 \mu \mathrm{g}$ & $800-1200 \mu \mathrm{g}$ & $>1200 \mu \mathrm{g}$ \\
\hline \multicolumn{4}{|c|}{$\begin{array}{l}\text { Notas: } \\
\text { - El factor determinante de la dosis es el criterio clínico ante la respuesta del paciente a la terapia mediante los diferentes parámetros } \\
\text { clínicos } \\
\text { - La dosis de los inhaladores presurizados dosis medidas es expresada en la cantidad de drogas liberada de la válvula y no la dosis } \\
\text { que llega al paciente }\end{array}$} \\
\hline
\end{tabular}

\section{Referencias}

1. Davies B, Brooks G, Devoy M. The efficacy and safety of salmeterol compared to theophylline: meta-analysis of nine controlled studies. Respir Med 1998; 256-63

2. Nelson HS. Beta-adrenergic bronchodilators. N Engl J Med 1995; 333: 499-506

3. Boulet LP. Long-versus short-acting beta 2-agonists. Implicationns for drug therapy. Drug 1994; 47: 207-22

4. Kesten S, chapman KR, Broder I, Cartier A, Hyland RH, Knight A, et al. A three-month comparison of twice daily inhaled formoterol versus four times daily inhaled albuterol in the management of stable asthma. Am Rev Respir Dis 1991; 144: 622-5

5. Wenzel SE, Lumry W, Manning M, Kalberg C, Cox F, Emmett A, et al. Efficacy, safety, and effects on quality of life of salmeterol versus albuterol in patients with mild to moderate persistent asthma. Ann Allergy Asthma immunol 1998; 80: 463-70

6. Shrewsbury S, Pyke S, Britton M. Meta-analysis of increased dose of inhaled steroid or addition of salmeterol in symptomatic asthma (MIASMA). BMJ 2000; 320: 1368-73

7. Greening AP, Ind PW, Northfield M, Shaw G. Added salmeterol versus higher-dose corticosteroid in asthma patients with symptoms on existing inhaled corticosteroid. Allen \& Hanburys Limited UK Study Group. Lancet 1994; 344: 219-24
8. Woolcock A, Lundback B, Ringdal N, Jacques LA. Comparison of addition of salmeterol to inhaled steroids with doubling of the dose of inhaled steroids. Am J Respir Crit Care Med 1996; 153: 1481-8

9. Kips JC, O'Connor BJ, Inman MD, Svensson K, Pauwels RA, O'Byrne PM. A long Term study of the antiinflamatory effect of llowdose budesonida plus formoterol versus high-dose budesonida in asthma. Am J Respir Crit Care Med 2000; 161: 996-1001

10. Lipworth BJ. Leukotriene-receptor antagonists. Lancet 1999; 353: 5762

11. Barnes NC, Miller CJ. Effect of leukotriene receptor antagonist therapy on the risk of asthma exacerbations in patients with mild to moderate asthma: an integrated analysis of Zafirlukast trials. Thorax 2000; 55: 478-83

12. Laviolette M, Malmstrom K, lu S, Chervinsky P, Pujet JC, Peszek I, et al. Montelukast added to inhaled beclomethasone in treatment of asthma. Montelukast/Beclomethasone Additivity Group. Am J Respir Crit Care Med 1999; 160: 1862-8

13. Virchow JC, Prasse A, Naya I, Summerton L, Harris A. Zafirlukast improves asthma control in patients receiving high-dose inhaled corticosteroids. Am J Respir Crit Care Med 2000; 162: 578-85 


\begin{tabular}{|c|c|c|}
\hline \multicolumn{3}{|c|}{$\begin{array}{c}\text { Anexo No. } 2 \\
\text { Medicamentos utilizados en asma y algunas de las formulaciones } \\
\text { disponibles en Costa Rica }\end{array}$} \\
\hline $\begin{array}{l}\text { Clase farmacológica } \\
\text { y nombre genérico }\end{array}$ & Presentación & Nombres comerciales \\
\hline \multicolumn{3}{|l|}{ Glucocorticoides inhalados } \\
\hline Budesonida & $\begin{array}{l}\text { 100mgr/inhalación } \\
\text { 200mgr/inhalación }\end{array}$ & Pulmicort $®$ \\
\hline Dipropionato de beclometasona & $\begin{array}{l}50 \text { mgr/inhalación } \\
250 \text { mgr/inhalación }\end{array}$ & $\begin{array}{l}\text { Becotide } \AA \\
\text { Becloforte } \AA\end{array}$ \\
\hline $\begin{array}{l}\text { Dipropionato de beclometasona } \\
\text { con hidrofluoroalcano como } \\
\text { propelente (partícula más fina) }\end{array}$ & $\begin{array}{l}50 \text { mgr/inhalación } \\
100 \mathrm{mgr} / \text { inhalación }\end{array}$ & Qvar ${ }^{\circledR}$ \\
\hline Propionato de fluticasona & $\begin{array}{l}50 \text { mgr/inhalación } \\
125 \text { mgr/inhalación } \\
250 \text { mgr/inhalación }\end{array}$ & Flixotide ${ }^{\circledR}$ \\
\hline \multicolumn{3}{|l|}{ Glucocorticoide combinado con beta 2} \\
\hline Budesonida + Formoterol (Turbohaler) & $\begin{array}{l}\text { 80mgr - 4.5mgr/inhalación } \\
\text { 160mgr - 4.5mgr/inhalación }\end{array}$ & Symbicor ${ }^{\circledR}$ \\
\hline Beclometasona + salbutamol & 50 mgr - 100mgr/inhalación & Ventide ${ }^{\circledR}$ \\
\hline $\begin{array}{l}\text { Fluticasona + Salmeterol } \\
\text { (Disco dispensador) }\end{array}$ & $\begin{array}{l}100 \mathrm{mgr}-50 \mathrm{mgr} / \mathrm{inh} \text { alación } \\
250 \mathrm{mgr}-50 \mathrm{mgr} / \mathrm{inh} \text { alación }\end{array}$ & Seretide ${ }^{\circledR}$ \\
\hline \multicolumn{3}{|l|}{ Cromonas inhalada } \\
\hline Cromoglicato de sodio & 1 mg/inhalación & $\begin{array}{l}\text { Cromovent } ₫ \\
\text { Intal } \AA\end{array}$ \\
\hline \multicolumn{3}{|l|}{ Cromonas nebulizada } \\
\hline Cromoglicato de sodio & $20 \mathrm{mg} / 2 \mathrm{cc}$ & Intal $\circledast$ \\
\hline \multicolumn{3}{|l|}{ Modificadores de leucotrienos } \\
\hline Zafirlukast & $\begin{array}{l}\text { 4mg/tableta masticable (niño) } \\
5 \mathrm{mg} / \text { tableta masticable (niño) } \\
\text { 10mg/tableta } \\
\text { 20mg/cápsula }\end{array}$ & $\begin{array}{l}\text { Singulair }{ }^{\circledR} \\
\text { Accolate }{ }^{\circledR}\end{array}$ \\
\hline \multicolumn{3}{|c|}{ Beta 2 agonista de acción corta inhalado } \\
\hline Salbutamol & 100mgr/inhalación & 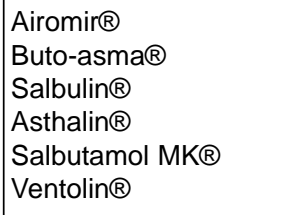 \\
\hline \multicolumn{3}{|l|}{ Beta 2 agonista de acción corta oral } \\
\hline $\begin{array}{l}\text { Clorhidrato de clenbuterol } \\
\text { Sulfato de salbutamol } \\
\text { Jarabe con } 2 \mathrm{mg} / \mathrm{cdta}\end{array}$ & $\begin{array}{l}\text { Tableta de } 20 \mathrm{mgr} / \mathrm{tableta} \\
\text { Jarabe de } 10 \mu \mathrm{gr} / \mathrm{cdta} \\
\text { Tableta de } 2 \text { y } 4 \mathrm{mg}\end{array}$ & Novegam ${ }^{\circledR}$ \\
\hline \multicolumn{3}{|l|}{ Beta 2 agonista acción corta nebulizada } \\
\hline Sulfato de salbutamol $5 \mathrm{mg} / \mathrm{cc}$ & & \\
\hline
\end{tabular}


continuación Anexo No 2

\begin{tabular}{|c|c|c|}
\hline $\begin{array}{l}\text { Clase farmacológica } \\
\text { y nombre genérico }\end{array}$ & Presentación & Nombres comerciales \\
\hline \multicolumn{3}{|l|}{ Beta 2 agonista acción prolongada } \\
\hline Formoterol & $\begin{array}{l}\text { 12mgr/cápsula } \\
4.5 \text { y 9mgr/inhalación }\end{array}$ & $\begin{array}{l}\text { Foradil } ® \\
\text { Oxis }{ }^{\circledR}\end{array}$ \\
\hline Salmeterol & 25mgr/inhalación & Serevent ${ }^{\circledR}$ \\
\hline \multicolumn{3}{|l|}{ Anticolinérgico inhalado } \\
\hline Bromuro de Ipratropium & 0.02mg/inhalación & Atrovent ${ }^{\circledR}$ \\
\hline \multicolumn{3}{|l|}{ Anticolinérgico nebulizado } \\
\hline Bromuro de Ipratropium & $0.5 \mathrm{mg} / 2 \mathrm{cc}$ & Atrovent ${ }^{\circledR}$ \\
\hline \multicolumn{3}{|l|}{ Metilxantinas } \\
\hline Teofilina & $\begin{array}{l}100 \mathrm{mg} / \mathrm{tableta} \\
125 \mathrm{mg} / \mathrm{tableta} \\
150 \mathrm{mg} / \mathrm{tableta} \\
200 \mathrm{mg} / \mathrm{tableta} \\
250 \mathrm{mg} / \mathrm{tableta} \\
300 \mathrm{mg} / \mathrm{tableta} \\
50 \mathrm{mg} / \mathrm{cdta}, 60 \mathrm{mg} / \mathrm{cdta}, \\
125 \mathrm{mg} / \mathrm{cdta}\end{array}$ & 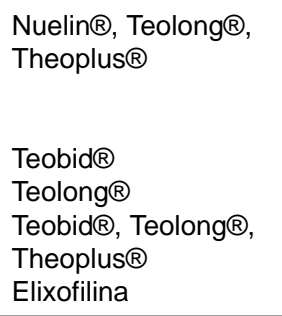 \\
\hline \multicolumn{3}{|l|}{ Glucocorticoides orales } \\
\hline Deflazacort & $\begin{array}{l}6 \mathrm{mg} / \mathrm{tab} l e t a \\
30 \mathrm{mg} / \mathrm{tableta} \\
1 \mathrm{mg} / \text { gota }\end{array}$ & Calcort $®$ \\
\hline Metilprednisolona & $\begin{array}{l}\text { 1mg/tableta } \\
4 \mathrm{mg} / \mathrm{tab} l e t a \\
16 \mathrm{mg} / \text { tableta }\end{array}$ & Medrol $®$ \\
\hline Prednisolona & $\begin{array}{l}1 \mathrm{mg} / \mathrm{tableta} \\
5 \mathrm{mg} / \mathrm{tableta} \\
25 \mathrm{mg} / \mathrm{tableta} \\
1 \mathrm{mg} / \mathrm{gota} \\
15 \mathrm{mg} / 5 \mathrm{cc}\end{array}$ & $\begin{array}{l}\text { Fisopred } \AA \\
\text { Prelone }{ }^{\circledR}\end{array}$ \\
\hline Prednisona & $\begin{array}{l}5 \mathrm{mg} / \mathrm{tab} \text { leta } \\
\text { 20mg/tableta } \\
50 \mathrm{mg} / \text { tableta }\end{array}$ & \\
\hline \multicolumn{3}{|l|}{ Esteroides intravenosos } \\
\hline Succinato sódico de metilprednisolona & $\begin{array}{l}500 \mathrm{mg} / 8 \mathrm{ml} \\
1000 \mathrm{mg} / 15 \mathrm{ml}\end{array}$ & Solu-medrol $₫$ \\
\hline Succinato Sólico de hidrocortisona & $\begin{array}{l}100 \mathrm{mg} / 2 \mathrm{ml} \\
250 \mathrm{mg} / 2 \mathrm{ml} \\
500 \mathrm{mg} / 2 \mathrm{ml}\end{array}$ & Solu-cortef $®$ \\
\hline Dexametasona & $4 \mathrm{mg} / \mathrm{ml}$ & Alin $®$ \\
\hline
\end{tabular}




\begin{tabular}{|c|c|c|}
\hline \multicolumn{3}{|c|}{ Anexo No. 3} \\
\hline Categoría de evidencia & Fuente de la evidencia & Definición \\
\hline A & $\begin{array}{l}\text { Estudios controlados } \\
\text { randomizados. (ECR) } \\
\text { Abundante cantidad de datos }\end{array}$ & $\begin{array}{l}\text { La evidencia es concluyente de } \\
\text { estudios controlados randomizados } \\
\text { que provea un patrón consistente } \\
\text { de hallazgos en la población por la } \\
\text { cual se realiza la recomendación. } \\
\text { Categoría A requiere un número } \\
\text { sustancial de estudios que involucre } \\
\text { un número sustancial de } \\
\text { participantes. }\end{array}$ \\
\hline B & $\begin{array}{l}\text { Estudios controlados } \\
\text { randomizados. (ECR) } \\
\text { Limitada cantidad de datos }\end{array}$ & $\begin{array}{l}\text { La evidencia es concluyente de } \\
\text { estudios de intervención en la cual } \\
\text { incluye solo un número limitado de } \\
\text { pacientes, o análisis de subgrupo de } \\
\text { estudios controlados randomizados } \\
\text { o meta-análisis de ECR. } \\
\text { En general, la Categoría B } \\
\text { corresponde a: } \\
\text { - Cuando existen pocos estudios } \\
\text { randomizados } \\
\text { - Cuando los estudios son } \\
\text { pequeños en tamaño } \\
\text { - Fueron realizados en población } \\
\text { que difieren de la población } \\
\text { blanco } \\
\text { Algunos de los resultados son } \\
\text { inconsistentes. } \\
\text { Estudios no randomizados }\end{array}$ \\
\hline C & $\begin{array}{l}\text { Estudios no randomizados } \\
\text { Estudios observacionales }\end{array}$ & $\begin{array}{l}\text { Evidencia proviene de resultados } \\
\text { de estudios no controlado o no } \\
\text { randomizados, o son estudios } \\
\text { observacionales }\end{array}$ \\
\hline D & Opinión del panel de consenso & $\begin{array}{l}\text { Esta categoría es usado solo en } \\
\text { casos donde la provisión de algunas } \\
\text { guías fueron de valor considerable, } \\
\text { pero la literatura disponible es } \\
\text { insuficiente para justificar su } \\
\text { colocación en una de las categorías } \\
\text { anteriores } \\
\text { El panel de consenso está basada } \\
\text { en la experiencia clínica o } \\
\text { conocimiento que no se deriva de } \\
\text { los criterios arriba mencionados }\end{array}$ \\
\hline $\begin{array}{l}\text { Adaptado del Global St } \\
\text { Health, National Herat, }\end{array}$ & $\begin{array}{l}\text { Asthma Management anc } \\
\text { Blood Institute. } 2002\end{array}$ & ention, National Institutes of \\
\hline
\end{tabular}


ISSN 0001-6002/2003/Supl.1/23-28

Acta Médica Costarricense, (C2003

Colegio de Médicos y Cirujanos

\title{
Enfermedad Pulmonar Obstructiva Crónica (EPOC)
}

\begin{abstract}
Ronald A. Chacón-Chaves, Mario Sibaja-Campos, Juan A. Dávila-Haas, Rodolfo Gutiérrez-Pimentel, Alexis Gutiérrez-Sanabria, Betty Rocha-Contreras, Gabriela Sánchez-Romero
\end{abstract}

Asociación Costarricense de Neumología y Cirugía de Tórax

\section{Definición}

La Enfermedad Pulmonar Obstructiva Crónica (EPOC) es una entidad caracterizada por limitación al flujo aéreo, la cual no es totalmente reversible. La limitación al flujo aéreo es usualmente progresiva y asociada con una respuesta inflamatoria anormal de los pulmones a partículas nocivas y gases.

El diagnóstico de EPOC debe considerarse en cualquier paciente que tiene síntomas de tos, producción de esputo o disnea y/o tiene historia de exposición a factores de riesgo para la enfermedad.

El diagnóstico se confirma por espirometría. La presencia de un VEF1 post broncodilatador menor al 80\% del valor predicho en combinación con un índice VEF1/CVF menor de 70\% confirma la presencia de limitación al flujo aéreo la cual no es totalmente reversible.

Cuando no se dispone de espirometría el diagnóstico debe hacerse usando los medios disponibles. Los síntomas y signos clínicos, tales como disnea y fase espiratoria prolongada pueden ayudar en el diagnóstico. Un flujo espiratorio pico (FEP) bajo es consistente con el diagnóstico de EPOC, pero es poco específico ya que puede ser causado por otras enfermedades y por dificultades para realizar la prueba.

\section{Clasificación de la severidad}

Para fines educativos se recomienda una clasificación simple en cuatro estadíos

El manejo del EPOC es principalmente guiado por los síntomas, y como existe una pobre correlación entre la limitación al flujo aéreo y la presencia de síntomas, la clasificación es más un abordaje práctico y debe verse como una herramienta educativa y una indicación muy general para el manejo.

Abreviaturas: Enfermedad Pulmonar Obstructiva Crónica (EPOC), Volumen Espiratorio Forzado en el primer segundo (VEF1), Capacidad Vital Forzada (CVF), Flujo Espiratorio Pico (FEP)

\begin{tabular}{ll}
\hline Estadio & Características \\
\hline 0: En riesgo & $\begin{array}{l}\text { Espirometría normal } \\
\text { Síntomas crónicos: tos, } \\
\text { expectoración }\end{array}$ \\
& VEF1/CVF $<70 \%$ \\
I. EPOC leve & CEF $>80 \%$ predicho \\
& VEF1/CVF $<70 \%$ \\
II. EPOC moderado & \\
& II A. $50 \%<$ VEF1 $<80 \%$ \\
& II B. $30 \%<$ VEF1 $<50 \%$ \\
& Con o sin síntomas crónicos \\
& VEF1/CVF $<70 \%$ \\
III. EPOC severo & VEF1 $<30 \%$ predicho, \\
& o presencia de insuficiencia \\
& respiratoria \\
& (pO2 $<60$ mm Hg + pCO2 \\
& $>50$ mm Hg) o \\
& signos clínicos de I.C.C. derecha \\
\hline
\end{tabular}

\section{Métodos diagnósticos}

\section{Historia Clínica:}

1. Exposición a factores de riesgo: tales como fumado ( activo y pasivo), humo de leña, exposiciones ocupacionales o ambientales ( polución ambiental), etc

2. Enfermedades previas, incluyendo asma, alergia, sinusitis, pólipos nasales, infecciones respiratorias en la infancia, otras enfermedades respiratorias: bronquiectasias, tuberculosis,etc)

3. Historia familiar de EPOC u otras enfermedades respiratorias crónicas. 
4. Patrón del desarrollo de síntomas: inicio en edad adulta, mayoría de los pacientes experimentan disnea progresiva , "resfríos" más frecuentes, y algunas limitaciones en las actividades sociales por algunos años antes de buscar consejo médico.

5. Historia de exacerbaciones u hospitalizaciones previas por enfermedades respiratorias.

6. Otras enfermedades: enfermedad cardíaca, colagenopatías.

7. Tratamientos médicos adicionales: beta bloqueadores, inhibidores enzima convertasa.

8. Impacto de la enfermedad en la vida del paciente: limitación de la actividad, pérdida de trabajo e impacto económico, efecto en las rutinas familiares, depresión o ansiedad.

9. Soporte social y familiar disponible para el paciente.

10. Posibilidades de reducción de los factores de riesgo, especialmente el fumado y la exposición al humo de leña.

\section{Examen Físico}

El examen físico puede ser normal. Algunos signos físicos pueden ser:

Taquipnea, pacientes a menudo muestran respiración con labios fruncidos

Cianosis central o descoloración de membranas mucosas

Anormalidades de pared torácica, que reflejan la hiperinflación pulmonar vista en el EPOC, que incluye costillas relativamente horizontalizadas, tórax en forma de tonel, y abdomen prominente.

Aplanamiento de los hemidiafragmas, puede estar asociado con retracción paradójica de la caja torácica inferior en inspiración, reducción de la matidez cardíaca.

Usualmente los pacientes tienen activación de músculos en reposo cuando están en decúbito dorsal. El uso de músculos escaleno y esternocleidomastoideo es un indicador de dificultad respiratoria. Presencia de sibilancias durante respiración es un indicador útil de limitación al flujo aéreo.

Reducción de murmullo vesicular.

Hígado puede ser palpable por desplazamiento caudal.

Edema de tobillos o miembros inferiores puede ser un signo de insuficiencia cardíaca derecha.

\section{Espirometría : limitación al flujo aéreo}

Debe realizarse espirometría en cualquier paciente que se sospeche EPOC. Para lograr identificar pacientes en forma temprana en el curso de la enfemedad, la espirometría debe realizarse en individuos que tienen tos crónica y expecto- ración aunque no presenten disnea, habiéndose descartado inicialmente por baciloscopías la posibilidad de una tuberculosis activa.

A pesar de que no mide el impacto completo de la enfermedad, la espirometría continúa siendo el standard de oro para el diagnóstico de la enfermedad y monitoreo de la evolución. Es el método mejor estandarizado, más reproducible, y la medición más objetiva de limitación al flujo aéreo disponible.

La espirometría debe estar disponible para el personal médico que tenga a cargo pacientes con EPOC, utilizando este procedimiento en pacientes que no tengan una exacerbación.

\section{Prueba de reversibilidad con broncodilatadores:}

1. Ayuda a excluir el diagnóstico de asma. Si el VEF1 regresa a rango normal previsto, después de la administración de broncodilatador, es probable que la limitación al flujo aéreo se deba a asma.

2. Para definir el pronóstico del paciente. Hay estudios que han demostrado que el VEF1 post broncodilatador es el marcador pronóstico más confiable que el VEF1 basal.

3. Para evaluar la respuesta potencial al tratamiento. Los pacientes que muestran una mejoría significativa en el VEF1 post broncodilatador es más probable que se beneficien del tratamiento con broncodilatadores y que tengan una respuesta positiva a glucocorticoides. Sin embargo, la respuesta individual a las prueba con broncodilatadores es influenciada por muchos factores y la falta de respuesta no excluye la respuesta en otra ocasión. Además, incluso pacientes que no muestran una respuesta significativa en una prueba con una dosis aguda de broncodilatador, se benefician sintomáticamente del uso a largo plazo de terapia con broncodilatadores.

\section{Radiografía de Tórax}

De poco valor diagnóstico, a menos que se evidencie enfermedad bulosa obvia, pero es útil en excluir otros diagnósticos. Los cambios radiológicos asociados con el EPOC incluye signos de hiperinsuflación (hemidiafragmas aplanados, aumento del volumen del espacio retroesternal, horizonta-lización delas costillas, aumento de los espacios intercostales, hiperclaridad de los pulmones), y falta de marcas vasculares.

El TAC de tórax, aunque no se recomienda de rutina, puede ayudar en el diagnóstico diferencial. Además es útil si se está contemplando procedimientos quirúrgicos como bulectomía o reducción de volumen pulmonar.

\section{Gases arteriales}

Deben considerarse en pacientes con VEF1 menor al 40\% del valor esperado o signos clínicos sugestivos de Insuficiencia Respiratoria o Insuficiencia Cardíaca Derecha. 


\section{Diagnóstico Diferencial}

1. Asma Bronquial.

2. Insuficiencia Cardíaca Congestiva.

3. Bronquiectasias.

4. Tuberculosis.

5. Bronquiolitis Obliterante.

6. Panbronquiolitis difusa.

Otras causas de tos crónica: Síndrome de goteo nasal posterior, Refuljo gastroesofágico, Sinusitis, Inducida por fármacos, Enfermedad Intersticial, Cáncer de Pulmón.

\section{Evaluación y control}

Las consultas de los pacientes con EPOC aumentan en frecuencia conforme la enfermedad avanza.

La evaluación y monitoreo de estos pacientes debe asegurar que los objetivos del tratamiento se están cumpliendo y debe incluir :

1. Exposición a factores de riesgo.

2. Progresión de la enfermedad o desarrollo de complicaciones.

3. Farmacoterapia , otros tratamientos médicos y revisión de la técnica de inhaloterapia .

4. Historia de crisis.

5. Co-morbilidades.

EPOC es una enfermedad progresiva por lo que es de esperar que la función pulmonar se deteriore a pesar del mejor cuidado posible.

Los síntomas y medidas objetivas de limitación al flujo aéreo deben evaluarse para determinar cuando modificar la terapia y para identificar complicaciones.

En cada visita, al igual que en la visita inicial , se debe realizar examen físico, evaluación y explicación de los síntomas.

El deterioro en la función pulmonar se logra evidenciar mejor por mediciones de espirometría periódicas, que se pueden realizar cada año, o antes, si hay deterioro marcado de síntomas o complicaciones.

\section{Gases arteriales}

No se realizan de rutina, sólo si en la valoración periódica existen datos clínicos sugestivos de Insuficiencia Respiratoria y/o Insuficiencia Cardíaca Derecha , oximetría de pulso con saturación de hemoglobina $<92 \%$ o VEF1 < $40 \%$.
Diagnóstico de Insuficiencia Cardíaca Derecha y/ o Cor Pulmonale

Existen elementos clínicos que sugieren el diagnóstico en el contexto de un paciente con enfermedad pulmonar obstructiva crónica :

Ingurgitación yugular y edemas podálicos. El diagnóstico puede ser apoyado con estudios de gabinete como: radiografía de tórax, electrocardiograma y ecocardiograma.

\section{TAC tórax, Gamma de pulmón}

La utilidad de estos estudios se reserva para pacientes que serán sometidos a cirugía de resección o reducción.

\section{Hematocrito}

Su importancia radica en encontrar pacientes con policitemia, lo que se manifiesta con hematocrito $>55$, lo cual se debe a la hipoxemia crónica.

\section{Estudios de Sueño}

Están indicados en pacientes que se sospeche la presencia concomitante de Apnea Obstructiva del Sueño, por la presen-cia de somnolencia diurna excesiva y roncopatía, obesidad, poliglobulia y/o signos de cor pulmonale en pacientes con obstrucción al flujo aéreo de leve a moderada intensidad, o bien la instauración de cefaleas matutinas al iniciar oxigenoterapia domiciliaria continua.

\section{Control farmacoterapia y otros tratamientos médicos}

Cada visita de seguimiento deberá incluir una discusión sobre el régimen terapéutico actual a fin de ajustar el tratamiento a medida que la enfermedad progresa. Deberá monitorizarse las dosis de los diferentes medicamentos, la adherencia al régimen, la técnica al inhalador, la efectividad del régimen actual para controlar los síntomas y los efectos secundarios.

\section{Historia de Crisis}

En cada visita se debe interrogar al paciente sobre exacerbaciones de su enfermedad, tanto las que son tratadas por él mismo paciente como aquellas que hayan sido tratadas por el médico. Deberá evaluarse la frecuencia, severidad y causa probable de las exacerbaciones. Se interrogará sobre el aumento del volumen del esputo y su purulencia, empeoramiento agudo de la disnea, el número de visitas no programadas a centros de atención de salud y al servicio de emergencia; y necesidad de hospitalizaciones(estancia, necesidad de ventilación mecánica y admisión a la unidad de cuidados intensivos).

\section{Otras Enfermedades}

Se deben considerar en los pacientes con EPOC, la presencia de condiciones que puedan empeorar la evolución u obligar 
a tomar consideraciones especiales en el tratamiento como el carcinoma bronquial, tuberculosis, apnea del sueño, insuficiencia cardiaca izquierda y diabetes mellitus.

\section{Manejo de EPOC estable}

El abordaje global del tratamiento del EPOC estable, debe caracterizarse por un aumento gradual escalonado, dependiendo de la severidad de la enfermedad, los objetivos del tratamiento deben lograrse con un mínimo de efectos secundarios y basarse en una evaluación individualizada de la severidad de la enfermedad y respuesta a varias terapias.

La clasificación de severidad propuesta incorpora una estrategia terapéutica dentro del manejo.

\section{Medidas Generales}

Cesación de fumado: Constituye la intervención preventiva y terapéutica más importante en el paciente ya diagnosticado, y es la principal medida preventiva para evitar el desarro-llo de la enfermedad. Incluso si la cesación se da en edades avanzadas o cuando ya existe deterioro funcional grave es posible mejorar la supervivencia respecto a los pacientes que continúan fumando. Siendo la primera medida para lograr el abandono el informar al paciente sobre sus efectos nocivos en el curso evolutivo del proceso.

Además de la sensibilización y la motivación, algunos pacientes requerirán terapia sustitutiva de nicotina y/o antidepresivos (bupropión).

Vacunación Antigripal (influenza): Se recomienda la administración anual dado que condiciona una disminución de la morbi-mortalidad durante los períodos epidémicos .

Vacunación Antineumocócica: Puede ser de utilidad, aunque su papel a largo plazo está por definirse.

\section{Tratamiento farmacológico}

El tratamiento farmacológico se usa para prevenir y controlar los síntomas, reducir la frecuencia y severidad de las complicaciones, mejorar el estado de salud, y mejorar la tolerancia al ejercicio. Ninguna de las medicaciones existentes ha demostrado modificar a largo plazo el decline en la función pulmonar que es la característica del EPOC. Sin embargo esto no debe excluir los esfuerzos en el uso de los medicamentos para el control de los síntomas.

Debido a que el EPOC es una enfermedad progresiva, aplican los siguientes principios

1. Debe haber un aumento gradual de en el tratamiento dependiendo de la severidad de la enfermedad.

2. El tratamiento regular necesita ser mantenido al mismo nivel por períodos prolongados a menos que se desarrollen efectos colaterales o que la enfermedad empeore.
3. La respuesta al tratamiento en el paciente individual es variable y debe ser monitorizado de cerca y ajustado regularmente.

\section{Broncodilatadores}

Son primordiales en el manejo sintomático del EPOC. Se dan en forma regular para prevenir y reducir lo síntomas y/o PRN para alivio de los síntomas.

Los efectos colaterales de los broncodilatadores son predecibles y dosis dependientes.

Los efectos adversos son menos probables y se resuelven mas rápidamente si se usa tratamiento inhalado comparado con tratamiento oral. Los pacientes con EPOC, tienden a ser mayores que pacientes con asma y con mas frecuencia presentan comorbilidad, por lo que el riesgo de desarrollar efectos colaterales es mayor.

Cuando el tratamiento se da por la ruta inhalada, se debe poner atención al uso efectivo del medicamento por lo que el entrenamiento en la técnica inhalatoria es esencial.

Todo tipo de broncodilatadores han demostrado aumentar la capacidad de ejercicio en EPOC, sin necesariamente producir cambios significativos en VEF1.

El uso regular con broncodilatadores de corta acción es más barato pero menos conveniente que el tratamiento con broncodilatadores de acción larga.

\section{Agonistas Beta 2}

La principal acción de los agonistas beta 2 es relajación del músculo liso de las vías aéreas por estimulación de los receptores beta 2 adrenérgicos, que aumentan el AMP cíclico y producen antagonismo funcional a la broncoconstricción. La terapia oral es más lenta en inicio y tiene mayores efectos colaterales que la terapia inhalada.

\section{Anticolinérgicos}

El efecto más importante de los medicamentos anticolinérgicos en pacientes con EPOC parece ser el bloqueo de los efectos de la acetilcolina en los receptores M3. Las drogas actuales también bloquean los receptores M2 y modifican la transmisión a un nivel pregangliónico, aunque estos efectos parecen ser menos importantes en EPOC.

El efecto broncodilatador de los anticolinérgicos inhalados de corta acción dura más que el efecto del los beta 2 agonistas, con algún efecto broncodilatador generalmente aparente hasta 8 horas después de la administración.

\section{Metilxantinas}

La controversia persiste acerca del efecto exacto de las metil xantinas. Pueden actuar como inhibidores de la fosfodiesterasa no selectivos, pero también se les ha reportado efectos no broncodilatadores, la significancia de los cuales es debatida. 
Datos acerca de la duración de acción para preparaciones convencionales o de libración lenta no estan disponibles en EPOC. Cambios en la función de músculos inspiratorios han sido reportados en pacientes tratados con teofilina, pero no es claro si esto se debe a cambios en los volumenes pulmonares dinámicos o efecto primario en los músculos. Todos los estudios que han demostrado eficacia de teofilina en EPOC fueron hechos con preparaciones de liberación lenta. La teofilina es efectiva en EPOC, pero debido a su toxicidad potencial, los broncodiltadores inhalados se prefieren si estan disponibles.

\section{Terapia combinada}

Combinar drogas con diferentes mecanismos y duración de acción puede aumentar el grado de broncodilatación con menos o equivalentes efectos colaterales. Una combinación de un agonista beta 2 y el anticolinérgico bromuro de ipratropium en EPOC estable produce mejoría mayor y más sostenida en VEF1 que cualquiera los medicamentos administrados en forma aislada y no existe evidencia que produzca taquifilaxia.

Terapia broncodilatadora de acuerdo a severidad de la enfermedad.

Se puede sugerir un tratamiento del EPOC con base en la clasificación de severidad de acuerdo al siguiente esquema

\begin{tabular}{ll}
\hline Estadios & Tratamiento recomendado \\
\hline TODOS & $\begin{array}{l}\text { Evitar factores de riesgo } \\
\text { Vacunación Influenza }\end{array}$ \\
$\begin{array}{l}\text { O: En riesgo } \\
\text { 1: EPOC leve }\end{array}$ & $\begin{array}{l}\text { Broncodilatadores de } \\
\text { acción corta PRN }\end{array}$
\end{tabular}

2: EPOC moderado IIA:

Tratamiento regular con uno o más broncodilatadores

Rehabilitación

Esteroides inhalados si hay respuesta significativa sintomática y función pulmonar

IIB: Tratamiento regular con uno o más broncodilatadores Rehabilitación Esteroides inhalados si hay respuesta sintomática, en la función pulmonar o si hay exacerbaciones a repetición

3: EPOC severo Tratamiento regular con uno o más broncodilatadores Esteroides inhalados si hay respuesta significativa Tratamiento de complicaciones Rehabilitación

Tratamiento oxígeno largo plazo (Insuficiencia Respiratoria) Considerar tratamiento quirúrgico

\section{Glucocorticoides}

Los efectos de los glucocorticoides son mucho menos dramáticos que en asma, y su papel en el manejo del EPOC estable es limitado a condiciones específicas.

\section{Glucocorticoides orales, ciclos cortos}

Hay evidencia, contraria a lo que se creía anteriormente, de que la respuesta a un ciclo corto de esteroides orales es un predictor muy pobre de la respuesta a largo plazo del tratamiento con esteroides inhalados en EPOC.

\section{Glucocorticoides orales, tratamiento crónico}

Basados en la falta de evidencia de beneficio, y la gran cantidad de efectos colaterales, el tratamiento a largo plazo con glucocorticoides orales no se recomienda en EPOC estable.

\section{Glucocorticoides inhalados}

Datos obtenidos de 4 estudios grandes en los efectos a largo plazo de esteroides inhalados en EPOC (Ciudad Copenhagen, EUROSCOP, ISOLDE, Lung Health Study II) dan evidencia de que el tratamiento regular con glucocorticoides es apropiado solamente en pacientes sintomáticos con una respuesta espirométrica documentada a glucocorticoides inhalados.

El tratamiento con glucocorticoides inhalados puede ser recomendado para pacientes con EPOC mas avanzado y exacerbaciones agudas a repetición.

\section{Otros tratamientos farmacológicos}

\section{Vacunas}

La vacunación con vacuna de influenza puede reducir enfermedad severa y muerte en pacientes con EPOC en cerca del $50 \%$. Las vacunas con virus muertos o vivos inactivados se recomineda ya que son mas efectivas en pacientes adultos mayores con EPOC.

\section{Antibióticos}

En varios estudios a largo escala controlados, el uso de antibióticos continuos profilácticos se mostró que no tenía efecto en la frecuencia de las exacerbaciones agudas de EPOC, por lo tanto tomando la evidencia actual, no se recomienda el uso de antibióticos, excepto para tratar las exacerbaciones infecciosas de EPOC y otras infecciones bacterianas.

\section{Mucolíticos}

A pesar de que algunos pocos pacientes con esputo viscoso se pueden beneficiar de mucolíticos, los beneficios globales parecen ser muy pequeños, por lo tanto basados en la evidencia actual, el uso en todos los pacientes con estos agentes no puede ser recomendado. 


\section{Antitusivos}

La tos, aunque a veces es un síntoma muy molesto en EPOC, tiene un papel protector significativo, por lo que el uso de antitusivos en EPOC estable está contraindicado

\section{Otros}

\section{Tratamiento no farmacológicos}

\section{Rehabilitación}

Los objetivos principales de la rehabilitación pulmonar son: reducir los síntomas, mejorar la calidad de vida y mejorar la participación física y emocional en las actividades diarias.

Un programa de rehabilitación adecuado debe incluir entrenamiento con ejercicios, consejo nutricional y educación.

\section{Terapia con oxígeno}

El tratamiento con oxígeno, uno de los principales tratamientos no farmacológicos para pacientes con Estadio III, puede ser administrado de tres maneras: 1. Terapia continua a largo plazo, 2. Durante ejercicio, y 3. Para alivio de la disnea. El objetivo primordial de la terapia con oxígeno es aumentar la $\mathrm{PaO} 2$ basal al menos a $60 \mathrm{~mm}$ hg a nivel del mar en reposo, y/o obtener una saturación de al menos $90 \%$.

La administración de oxígeno a largo plazo (más de 15 horas por día) a pacientes con insuficiencia respiratoria crónica, se ha demostrado que aumenta la sobrevida. También puede tener un impacto beneficioso en la hemodinamia, las características hematológicas, la capacidad de ejercicio, la mecánica pulmonar y el estado mental.

La terapia con oxígeno a largo plazo se introduce generalmente en pacientes con EPOC severo Estadio III, para pacientes que tienen:

- $\quad \mathrm{PaO} 2$ por debajo de $55 \mathrm{~mm}$ hg o una saturación por debajo de $88 \%$, con o sin hipercapnia

- $\quad \mathrm{PaO} 2$ entre 55 y $60 \mathrm{~mm}$ hg o saturación de $89 \%$, si hay evidencia de hipertensión pulmonar, edema periférico que sugiera insuficiencia cardíaca congestiva, o policitemia (hematocrito > 55\%)

\section{Soporte ventilatorio}

Varios estudios científicos han evaluado el uso de soporte ventilatorio no invasivo en el manejo de EPOC estable y no hay evidencia convincente de que este tipo de terapia tenga un rol en el manejo de pacientes con EPOC estable.

\section{Tratamientos quirúrgicos}

\section{Bulectomía:}

Es un procedimiento quirúrgico antiguo para enfisema buloso. Al remover una gran bula que no contribuye al intercambio gaseoso, el parénquima pulmonar adyacente se descomprime. La bulectomía se puede realizar toracoscópicamente. En pacientes seleccionados cuidadosamente, este procedimiento puede ser efectivo en reducir la disnea y mejorar la función pulmonar.

\section{Cirugía de Reducción de Volumen Pulmonar}

En este procedimiento, partes del pulmón se resecan para reducir la hiperinflación, haciendo de los músculos respiratorios unos generadores de presión mas efectivos al mejorar su eficiencia mecánica. Además se aumenta la presión elástica del pulmón y por lo tanto mejoran las tasas de flujos expiratorios.

\section{Transplante pulmomar}

En pacientes adecuadamente seleccionados con EPOC muy avanzado, el trasplante de pulmón ha demostrado mejorar la calidad de vida y la capacidad funcional. Esta limitado por la escasez de donadores y por su altísimo costo.

\section{Referencias}

Basado en Global Initiative for Chronic Obstructive Lung Disease (GOLD), Global Initiative for the diagnosis, management, and prevention of chronic obstructive pulmonary disease. National Heart Lung Blood Institute/WHO.Publication 2701, April 2001.

1. Burrows B, Niden AH, Barclay WR, Kasik JE. Chronic obstructive lung disease II. Relationships of clinical and physiological findings to the severity of airways obstruction. Am Rev Respir Dis 1965; 91:66578.

2. Medical Research Council. Definition and classification of chronic bronchitis for clinical and epidemiological purposes: a report to the Medical Research Council by their Committee on the Aetiology of Chronic Bronchitis. Lancet 1965; 1:775-80.

3. Celli BR, Rassulo J, Make BJ. Dyssynchronous breathing during arm but not leg exercise in patients with chronic air flow obstruction. $\mathrm{N}$ Engl J Med 1986; 314:1485-90.

4. Badgett RC, Tanaka DV, Hunt DK, Jelley MJ, Feinberg LE, Steiner JF, et al. Can moderate chronic obstructive pulmonary disease be diagnosed by history and physical findings alone? Am J Med 1993; 94:18896.

5. Standardization of spirometry, 1994 update. Am J Respir Crit Care Med 1995; 152:1107-36.

6. Kelly CA, Gibson GJ. Relation between FEV 1 and peak expiratory flow in patients with chronic obstructive pulmonary disease. Thorax 1988; 43:335-6.

7. Lal S, Ferguson AD, Campbell EJM. Forced expiratory time; a simple test for airways obstruction. BMJ 1964; 1:814-7.

8. Hansen EF, Phanareth K, Laursen LC, KokJensen A, Dirksen A. Reversible and irreversible airflow obstruction as predictor of overall mortality in asthma and chronic obstructive pulmonary disease. Am J Respir Crit Care Med 1999; 159:1267-71.

9. Anthonisen NR, Wright EC. Bronchodilator response in chronic obstructive pulmonary disease. Am Rev Respir Dis 1986; 133:814-9.

10. Sourk RL, Nugent KM. Bronchodilator testing: confidence intervals derived from placebo inhalations. Am Rev Respir Dis 1983; 128:1537.

11. Roberts CM, Bugler JR, Melchor R, Hetzel ML, Spiro SG. Value of pulse oximetry for long-term oxygen therapy requirement. Eur Respir J 1993; 6:559-62. 


\section{Guías para el manejo de la Neumonía Adquirida en la Comunidad (NAC) en Adultos}

Antonio Solano, Marlene Jiménez, Carlos Dobles, Mauricio Saldarriaga, Álvaro Avilés, Juan Villalobos, Jorge Mora, Gisela Herrera, Emilio Guevara, Jorge Ramírez, Juan I Padilla, Enrique Vives, Ronald Chacón, Manuel Rojas, Bernal Cordero, Jaime Fernández, Carlos Wu, Alfredo Messino

Asociación Costarricense de Neumología y Cirugía de Tórax

\section{Introducción}

La neumonía adquirida en la comunidad es una de las patologías médicas que genera más controversia en su manejo. Dada su alta frecuencia y mortalidad, este documento pretende dar una guía práctica estandarizada, basada en evidencia al manejo del paciente con esta enfermedad.

\section{Epidemiología}

Se reportan de dos a tres millones de casos de neumonía por año en los Estados Unidos, requiriendo ingreso hospitalario en cerca de un $20 \%$. La mortalidad oscila desde un $2 \%$ a un $30 \%$ (14\% promedio) en pacientes hospitalizados. En este mismo país se reporta como la sexta causa de muerte.

A nivel mundial la infección del tracto respiratorio inferior se le considera como la principal causa de muerte, en Costa Rica desconocemos la magnitud exacta de su incidencia y mortalidad.

\section{Definición}

Infección aguda del parénquima pulmonar que está asociada al menos con dos de los siguientes síntomas de infección aguda: fiebre o hipotermia, sudoración, tos con o sin expectoración, cambios en el color de la expectoración en tosedores crónicos, disnea, dolor torácico

Presencia de otros síntomas inespecíficos: fatiga, mialgias, dolor abdominal, anorexia, cefalea.

Infiltrados agudos en la radiografía de tórax, hallazgos físicos consistentes con neumonía: crépitos y soplo tubario. Todo esto en un paciente no hospitalizado o viviendo en un asilo por 14 días o más antes de su ingreso.

\section{Diagnóstico}

\section{- Historia Clínica}

Incluir dentro del interrogatorio datos específicos que puedan sugerir que la neumonía es por gérmenes no usuales: contacto con aves, trabajo con animales, viajes recientes, vacunación o infección reciente por varicela

\section{- Síntomas}

Son inespecíficos. Generalmente se encuentra: fiebre, escalofríos, tos, esputo purulento, dolor torácico, disnea.

Síntomas respiratorios superiores como rinorrea, estornudos, odinofagia. vómitos, mialgias, cefalea

\section{- Examen físico}

La percusión muestra matidez, crépitos, vibraciones vocales aumentadas, respiración bronquial (soplo tubario).

Presentes en una tercera parte de los pacientes internados y 5-10\% de los pacientes ambulatorios

\section{Métodos diagnósticos}

\section{Radiografía de tórax:}

- Indicada en todos los pacientes para hacer diagnóstico siempre y cuando sea accesible

- Algunas veces sugiere agente causal (abscesos, infiltrados intersticiales, etc).

- Descarta o detecta enfermedades pulmonares asociadas.

\section{Frotis y cultivo de esputo}

- De gran utilidad para el tratamiento, seguimiento, conocimiento epidemiológico de los agentes etiológicos y la resistencia a los antibióticos

- Antes del inicio del tratamiento antibiótico

- Se requiere personal entrenado para su interpretación

- Siempre escoger las muestras con criterio citológico (excepto para Legionella o micobacterias)

- Estudio por M. Tuberculosis para pacientes seleccionados (principalmente tos de más de un mes de evolución y cuadro radiológico sugestivo). 
- Se debe de inducir esputo en pacientes con sospecha de Pneumocystis carinii

- Aspirado transtraqueal solo en casos seleccionados y personal entrenado

- Aspirado de traqueostomía, aspirado de TET, aspirado nasotraqueal en casos específicos

- Pacientes hospitalizados con neumonía severa antes de inicio de tratamiento (clase PORT. IV y V)

- Realizar estudios por hongos o parásitos en pacientes específicos

\section{Toracosentesis}

- Con frotis y cultivo por piógenos

- Medición de pH

- Diferencial de leucocitos

- Esto en pacientes que tienen NAC más derrame pleural que creemos es paraneumónico complicado

\section{Búsqueda de Legionella}

Estudio por Legionella:

- Pacientes seleccionados como gravemente enfermos sin diagnóstico alternativo

- Generalmente mayores de 40 años

- Inmunocomprometidos

- $\quad$ Factores epidémicos

- Cuadro clínico incluye fiebre, escalofríos, cefalea y síntomas del tracto respiratorio superior que preceden a la Neumonía.

- Inmunofluorescencia directa de las secreciones bronquiales

- Títulos de anticuerpos presentes en orina

\section{Broncoscopia}

- Cuando se requiere que la muestra sea lo menos contaminada posible

- Poca respuesta a tratamiento previo

- Pacientes clase V sin respuesta a tratamiento antibiótico amplio donde se sospecha gérmenes inusuales

\section{Otras pruebas de laboratorio}

A todos los pacientes que requieren internamiento: hemograma completo, gasometría arterial, función renal, electrolitos, glucemia son necesarios para clasificación PORT y por tanto para pronóstico.
Decisión de ingreso o manejo ambulatorio

Sugerimos la utilización de puntaje a través del sistema de predicción PORT (Fine. N Engl J Med 1997; 336), con el cual los pacientes se estratifican en 5 clases según severidad, los de riesgo I y II se manejarán en forma ambulatoria, los de riesgo III requiere un tiempo de observación en el servicio de emergencias y según sea su evolución se decide su ingreso o manejo ambulatorio.

La mortalidad para las clases I-III es de $(0.1 \%-2.8 \%)$, clase IV es de (8.2\% al 9.3\%) y las clase $\mathrm{V}$ es de (27\% $-31.1 \%)$

\begin{tabular}{|c|c|}
\hline \multicolumn{2}{|c|}{ Clasificación PORT } \\
\hline & Puntos \\
\hline \multicolumn{2}{|l|}{ 1. Factores demográficos } \\
\hline $\begin{array}{l}\text { Edad } \\
\text { hombres } \\
\text { mujeres } \\
\text { Hogar de ancianos }\end{array}$ & $\begin{array}{l}\text { años de edad } \\
\text { años de edad - } 10 \\
+10\end{array}$ \\
\hline \multicolumn{2}{|l|}{ 2. Comorbilidad asociada } \\
\hline $\begin{array}{l}\text { Neoplasias } \\
\text { Hepatopatías } \\
\text { ICC } \\
\text { ECV } \\
\text { Nefropatías }\end{array}$ & $\begin{array}{l}+30 \\
+20 \\
+20 \\
+15 \\
+10\end{array}$ \\
\hline \multicolumn{2}{|l|}{ 3. Exámen físico } \\
\hline $\begin{array}{l}\text { Estado mental alterado } \\
\text { F.respiratoria }>30 / \text { min } \\
\text { Presión sistólica }<90 \\
\text { Temperatura }<35 \text { ó }>40{ }^{\circ} \mathrm{C} \\
\text { Pulso }>125 \text { minuto }\end{array}$ & $\begin{array}{l}+20 \\
+20 \\
+20 \\
+15 \\
+10\end{array}$ \\
\hline \multicolumn{2}{|l|}{ 4.Laboratorio y $\mathrm{Rx}$} \\
\hline $\begin{array}{l}\mathrm{pH} \text { arterial }<7.35 \\
\mathrm{~Pa} O 2(<60 \mathrm{mmHg}) \\
\text { Sodio }<130 \mathrm{mEq} / \mathrm{l} \\
\mathrm{NU}>30 \mathrm{mg} / \mathrm{dl} \\
\text { glucosa }>250 \mathrm{mg} / \mathrm{dl} \\
\text { hematocrito }<30 \% \\
\text { derrame Pleural }\end{array}$ & $\begin{array}{l}+30 \\
+20 \\
+20 \\
+10 \\
+10 \\
+10 \\
+10\end{array}$ \\
\hline \multicolumn{2}{|c|}{$\begin{array}{l}\text { Sin comorbilidad asociada (cáncer, ICC, } \\
\text { hepatopatía, enfermedad cerebrovascular, renal) } \\
\text { Signos vitales estables } \\
\text { Estado mental normal }\end{array}$} \\
\hline $\begin{array}{l}\text { Clase II : } \\
\text { Clase III : } \\
\text { Clase IV: } \\
\text { Clase V: }\end{array}$ & $\begin{array}{l}\text { Ž } 70 \text { puntos } \\
71-90 \text { puntos } \\
91-130 \text { puntos } \\
>130 \text { puntos }\end{array}$ \\
\hline
\end{tabular}


ESQUEMAS DE MANEJO (ver esquemas)

1- Pacientes que requieren hospitalizarse : casos habituales

Severidad: Moderada

- PORT III (Revalorar conducta en 72 hrs.)

$<60$ años y sanos

Penicilina Na+( 20 millones /día )*

( Clindamicina )

$\pm$

Macrólido ( Doxiciclina)

* Se puede utilizar Ampicilina o Cefotaxime en sospecha de $\mathrm{H}$. influenzae o bien bajo indicación infectológica

\section{- PORT IV}

( 60 años y/o patología asociada ó falla terapéutica)

$$
\text { Cefotaxime }
$$

Macrólido

Alternativa : Quinolona IV

y vía oral (Tratamiento oral y egreso)

\section{SEVERA}

\section{PORT V}

Internar a UCI

Cefotaxime

$+$

Quinolona IV y VO (Tx oral y egreso)

Vancomicina *
1- Pacientes especiales

que requieren hospitalizarse : casos

- VIH ( + )

TMP/SMX

$+$

Cefotaxime

Buscar BK y hongos

- VIH ( - )

- Transplantados

- Neutropénicos

$$
\text { - F Q P }
$$

Ceftazidime

Aminoglucósido** (Quinolona)

+ Vancomicina*

** Sustituir por quinolona si es de riesgo para nefrotoxicidad temprana: creatinina $>$ de 2 o aclaramiento $<$ de 50

\section{Broncoaspiración*}

Clindamicina

( Penicilina $\mathrm{Na}+$ )

Aminoglucósido

Cefotaxime

* Si causa neumonía severa se trata como Clase V + Clindamicina

- Embarazo

PORT IV

Penicilina

$+$

Macrólido

(luego 1er trimestre)

PORT V

Cefotaxime

$+$

Macrólido 


\section{2- Pacientes de tratamiento ambulatorio}

Alternativas de elección:

- $\quad$ Macrólido

- $\quad$ Amoxicilina

- Doxiciclina

- Quinolona oral*

En la embarazada considere: Amoxicilina, Macrólido ( 2do o 3er trimestre ), de lo contrario hospitalizar.

* Solo en caso de completar esquema iniciado intravenoso

Algunas preguntas importantes de responderse antes de indicar el tratamiento ambulatorio:

¿ El paciente vive solo?

¿ Es capaz de cuidarse a si mismo o al menos de pedir ayuda ?

¿Alguien competente lo atiende o puede ayudarlo ?

¿ Puede monitorizarse en su hogar ?

¿ Dispone de transporte?

¿ Sus condiciones familiares son adecuadas para su recuperación ?

¿ Tiene acceso fácil a un centro de salud ?

\section{Referencias}

1. Fine MJ et al A prediction rule to identify low-risk patients with community-acquired pneumonia. N Engl J Med 1997; 336:243-50

2. Fine MJ et al. prognosis and outcomes of patients with communityacquired pneumonia JAMA 1996; 275:134-41

3. Bartlett $\mathrm{J}$ et al .Practice Guidelines for the management of CommunityAcquired Pneumonia in Adults. Clin Infect Dis 2000; 31:347-82

4. Niederman MS et al. Guidelines for the initial empiric therapy of community-acquired pneumonia: proceedings of an American Thoracic Society Consensus Conference .Am Rev Resp Dis 1993; 148: 1418-26

5. British Thoracic Society . Guidelines for the management of with community-acquired pneumonia in adults admitted to the hospital. $\mathrm{Br} \mathrm{J}$ Hosp Med 1993; 4:25 
ISSN 0001-6002/2003/Supl.1/33-34

Acta Médica Costarricense,(C2003

Colegio de Médicos y Cirujanos

\title{
Tumores Pared Torácica
}

\author{
Marco Herrera-Rodríguez, John Miranda-Chavarría \\ Asociación Costarricense de Neumología y Cirugía de Tórax
}

\section{Frecuencia}

Si bien los tumores de pared torácica no son muy frecuentes, y representan aproximadamente de un 2 a un 5\% de todos los tumores del tórax, son de manejo complejo por lo que ameritan un estudio detallado y un abordaje exhaustivo para su corrección.

\section{Etiología}

Los reportes de malignidad de los tumores primarios de la pared torácica, oscilan entre un 50 y un $80 \%$. En los estudios limitados a tumores esqueléticos, la incidencia de malignidad, es significativamente menor.

Debe tenerse en mente que los tumores pueden ser benignos o malignos, y estos primarios de la pared, o bien metastáticos. Siempre se debe buscar o descartar que se encuentre un tumor pulmonar subyacente, (T3 de pulmón), o uno lejano, (mama, riñón, colon y sarcomas), siendo estos tratados solo como paliación de los síntomas principalmente, no afectando en nada el pronóstico del tumor primario. Sólo el 2\% de los tumores se originan en la pared torácica, y cerca del 50\% provienen de los tejidos blandos.

\section{Diagnóstico}

\section{SINTOMATOLOGÍA}

Los síntomas más frecuentes de presentación son la sensación de aparición de masa y el dolor local o referido, que a veces pasan desapercibidos por el médico tratante, o son minimizados por el paciente, sin embargo están presentes hasta en un $40 \%$

Puede existir historia de trauma reciente, que se asocia incidentalmente, no causalmente con el hallazgo del tumor, ya que se le brinda atención a esta parte de la economía debido al trauma, convirtiendo el tumor en un hallazgo; la historia clínica, es fundamental, para establecer la duración de la masa, su velocidad de crecimiento, otra sintomatología asociada, ya sea esta local o lejana al sitio de la aparición de la lesión.

\section{Estudios de laboratorio y gabinete}

En cuanto al laboratorio, los exámenes más comunes son el Hemograma, la fosfatasa alcalina, que puede darnos una idea de la destrucción ósea, y los que se necesiten para completar el estudio de la enfermedad que se sospeche.

Los estudios de gabinete rutinarios son aquellos que delimitan y ubican la lesión, como las placas postero-anteriores (P.A.) y lateral (del lado afectado) del tórax. La tomografía axial computadorizada (TAC), con medio de contraste, es fundamental para ver las relaciones del tumor con estructuras subyacentes, sus dimensiones en los tres ejes, (P.A., lateral, y supero-inferior), también la densidad del tumor, así como la presencia de otros tumores dentro del tórax, y la presencia de adenopatías mediastinales.

El papel de la resonancia magnética nuclear (RMN), no supera a la TAC, pero es necesario realizarla en algunas circunstancias, como cuando el paciente es alérgico al medio de contraste, cuando se sospecha que hay infiltración del opérculo torácico, cuando hay infiltración de la axila, y cuando hay infiltración de canal raquídeo.

Las pruebas de función pulmonar, son especialmente útiles para evaluar la enfermedad pulmonar que ya posea el paciente, aunque aún con resecciones de pared mayores a 400 $\mathrm{cm}^{2}$, no hay variación significativa en la función pulmonar postoperatoria.

La gammagrafía ósea es importante para descubrir otras lesiones que no se ven en estudios radiológicos sencillos, y que pueden significar un cambio en la modalidad terapéutica que se vaya a implementar.

\section{Tipo de tumores}

Los tumores primarios de la pared torácica, se presentan clínicamente como tumefacción, y dolor, manifestaciones que se encuentran hasta en un $40 \%$ de los pacientes.

Los tumores primarios benignos de la pared torácica son: condroma, osteocondroma, displasia desmoide y fibrosa, y la histiocitosis X.

Los tumores primarios malignos se enumeran a continuación: plasmacitoma, condrosarcoma, osteosarcoma, histiocitoma fibroso maligno, rabdomiosarcoma, sarcoma de Swing, y tumor de Askin.

El osteosarcoma se presenta usualmente en gente joven, tiene crecimiento rápido, destrucción ósea mal delimitada, puede haber respeto por la cortical, calcificaciones intramurales. 
Los tumores secundarios de la pared torácica (metastáticos) son el carcinoma de pulmón, debe siempre tenerse en cuenta, que la pared puede encontrarse afectada por un tumor pulmonar subyacente, que debe estudiarse y tratarse según su protocolo de manejo, las metástasis de tumores extratorácicos, en especial los provenientes de riñón, colon y sarcomas de otras localizaciones y la infiltración por carcinoma de mama.

\section{Tratamiento quirúrgico}

El tratamiento de elección consiste en la resección radical primaria de la lesión en la mayoría de los casos.

El manejo quirúrgico, y la técnica de reconstrucción dependen del tamaño del tumor, de su estirpe histológica y de su localización. El objetivo siempre será la resección completa en bloque con márgenes de al menos $4 \mathrm{~cm}$. en caso de los tumores malignos, y de al menos $2 \mathrm{~cm}$. en los casos comprobados de benignidad. La biopsia por congelación de los bordes de tejidos blandos es recomendable, cuando se cuente con los medios. La resección debe incluir el espesor total de la pared, con todos los planos que esta contiene, debe también incluir los trayectos de biopsias y punciones. La recidiva, o la resección incompleta deben tratarse quirúrgicamente, siempre que no exista otro medio oncológico de tratamiento.

\section{Tratamiento adyuvante}

La quimioterapia, y la radioterapia tienen un papel limitado en los tumores primarios malignos de la pared torácica; pueden desempeñar un rol importante en las recidivas locales de tumores sensibles, y de algunos secundarios.

Los sarcomas por regla general son indiferentes a estas variedades terapéuticas. Algunos tumores secundarios son sensibles a una o ambas formas de tratamiento, lo que debe individualizarse. El neuroepitelioma periférico y el rabdomiosarcoma, son sensibles a la quimioterapia de inducción, por lo que se recomienda aplicarla antes del procedimiento quirúrgico.

\section{Referencias}

1. Shields, T. General Thoracic Surgery. Cuarta Edicion. Williams \& Wilkins. USA 1994

2. Pearson, F. Thoracic Surgery. USA. 1995

3. Pearson, F. Seminars in Thoracic and Cardiovascular Surgery. Vol 4, No.1. Enero 1992

4. Benfield, J. Chest Surgery Clinics of North America. Febrero 1992. 
ISSN 0001-6002/2003/Supl.1/35-39

Acta Médica Costarricense,@2003

Colegio de Médicos y Cirujanos

\section{Cáncer de Pulmón}

José A. Mainieri-Hidalgo, Alejandro Brenes-Dittel

Asociación Costarricense de Neumología y Cirugía de Tórax

\section{Detección}

\section{Población de alto riesgo}

La población con mayor riesgo está formada por personas de 45 años o más que han sido fumadores por más de 20 años.

\section{Métodos de detección}

Ningún método ha demostrado ser altamente efectivo para detección temprana masiva. La combinación de la citología de esputo, y la radiografía de tórax son útiles para detectar esta neoplasia.

La recomendación como resultado del Proyecto de la Clínica Mayo es la combinación de citología del esputo cada cuatro meses y una radiografía del tórax anual para los pacientes del grupo de alto riesgo.

Actualmente los estudios demuestran que el TAC de tórax es un estudio más sensible y específico, sin embargo no se ha definido claramente la normativa para la aplicación sistemática de este estudio.

Otro método importante que cabe mencionar con relación al diagnóstico del cáncer pulmonar es la broncoscopia. La diferencia con los dos anteriores que se realizan en pacientes asíntomáticos, es que la broncoscopia está indicada en presencia de síntomas tales como tos crónica con radiografía de tórax anormal, hemoptisis, atelectasia, neumonías recurrentes, estridor o sibilancia localizada y anormalidades sospechosas en la radiografía de tórax.

La propuesta en este sentido es: detectar a la población de alto riesgo y realizarle radiografía de tórax y la citología del esputo. Así como comunicar a los médicos la obligación como parte de la buena practica médica, de identificar los grupos de riesgo, dar educación y ordenar estudios de detección temprana de rutina.

\section{Métodos de Diagnóstico}

\section{Radiografía postero-anterior y lateral de tórax}

La radiografía del tórax dependiendo de la afección tumoral permite detectar:

1. Alteraciones bronquiales: atelectasias, neumonitis obstructiva.
2. Alteraciones en el parénquima pulmonar: nódulos, masas e infiltrados pulmonares

3. Alteraciones extrapulmonares: derrame pleural, erosiones costales e invasión de pared torácica

4. Alteraciones hiliares: prominencias hiliares, masas e infiltrados

5. Alteraciones mediastinales: ensanchamiento, masas, desplazamiento de estructuras mediastinales

La incidencia lateral permite detectar hasta un 10\% de lesiones no visibles en la radiografia postero anterior, por lo que debe ordenarse de rutina.

La sensibilidad en general de la radiografía de tórax para la detección temprana del cáncer de pulmon es baja, por lo que no permite excluir este diagnóstico. Este estudio falla en demostrar lesiones traqueo bronquiales.

\section{Tomografía Lineal}

Es útil para definir lesiones que se sospechan, pero no se confirman con la placa simple. Este estudio ha caído en desuso, donde se dispone de la Tomografía Axial.

\section{Tomografía axial computarizada (TAC)}

Es especialmente útil para valorar:

1. Mediastino para detectar la presencia de adenomegalias. El estudio es sensible pero poco específico por lo que la presencia de adenopatías mediastinales en el TAC debe complementarse con biopsia.

2. Nódulos pulmonares incluyendo algunos no visibles en la radiografía de tórax y definir con precisión sus características como tamaño, bordes, densidad, calcificaciones y con limitaciones, la extensión a pared torácica o hacia el mediastino de una masa pulmonar

3. Este estudio no es sensible para confirmar la invasión de algunas estructuras como grandes vasos y pared torácica, por lo que no debe contraindicarse la cirugía por un TAC a menos que se observe con claridad que la masa rodea circunferencialmente una estructura vital como aorta, tráquea o esófago. 


\section{Resonancia magnética}

La resonancia magnética no es superior al TAC. Está indicada cuando se sospecha:

1. Afección de grandes vasos.

2. Afección de pared torácica.

3. Compromiso de la columna vertebral.

4. Estudio vascular en un paciente con alergia al medio de contraste.

\section{Citología del esputo}

Es un estudio sencillo, útil y poco costoso que puede ser utilizado ampliamente como método de detección, sin embargo su sensibilidad es baja. Permite detectar la presencia de células neoplásicas en el esputo sobre todo en tumores grandes y de localización central, pero es poco efectiva para tumores pequeños o periféricos. La sensiblidad de este estudio es mayor con la recolección de tres muestras y su rentabilidad diagnóstica no aumenta con más. Se colecta el primer esputo de la mañana. La recolección del esputo inducido (15 $\mathrm{ml}$ de $\mathrm{NaCl}$ al 3\%) aumenta la sensibilidad del estudio.

\section{Broncoscopia}

Es el método más eficiente para obtener una muestra para el diagnóstico histológico. Su sensibilidad depende del tamaño de los tumores, estirpe histológica y método utilizado para tomar las muestras.

La mayor rentabilidad diagnóstica se obtiene combinando el aspirado bronquial para citología, cepillado bronquial, la biopsia (endobronquial o transbronquial), y la punción con aguja (transbronquial); dirigiendo la toma de las muestras con fluoroscopía.

Permite además valorar la movilidad de las cuerdas vocales, si hay invasión o compresión extrínseca de la tráquea, la carina, los bronquios principales, lobares y segmentarios y la detección de tumores sincrónicos.

\section{Citología del derrame pleural}

El derrame pleural que se asocia con un cáncer pulmonar puede ser de etiología maligna o para maligna por lo que su diferenciación es fundamental. La presencia de un derrame pleural maligno, según la clasificación TNM, cataloga el caso como un $\mathrm{T} 4 \mathrm{y}$ en un estadio III b (irresecable).

La citología del líquido pleural es un estudio rápido, sensible y barato para clasificar el derrame. Su sensibilidad aumenta con la toma de muestras seriadas.

\section{Biopsia cerrada de pleura}

No adiciona mayor utilidad a la citología del líquido pleural sin embargo puede ser considerada cuando no se disponga de toracoscopia y en casos de pacientes ambulatorios en los que se desea evitar un internamiento.

\section{Toracoscopía}

Permite obtener muestras para diagnóstico histológico de lesiones intratorácicas de la pleura, del pulmón y del mediastino; sobre todo cuando la lesión pulmonar es periférica o se acompaña de invasión o derrame pleural. El método permite por un pequeño orificio observar y valorar la superficie pulmonar y la pleura, aspirar líquido, tomar biopsias de pleura, de adenomegalias y masas mediastinales y de lesiones pulmonares periféricas. Es ideal para resecar metástasis pulmonares periféricas y tumores primarios benignos o para pacientes que no toleran resecciones amplias.

\section{Mediastinoscopía}

Es un método quirúrgico útil para obtener material para biopsia en casos en que el TAC detecte adenopatías mediastinales. Permite tomar muestras de los ganglios linfáticos que se localizan en posición pretraqueal, para-traqueal, traqueobronquial y en la subcarina.

Aunque algunos autores recomiendan realizarla de rutina antes de una toracotomía por cáncer, con la sensibilidad que tiene la TAC para detectar presencia de adenomegalias en el mediastino, se puede dejar sólo para cuando se demuestra la presencia de las mismas.

\section{Mediastinotomía}

Cuando se presenta una masa en el mediastino anterior, está contraindicada la mediastinoscopía supraesternal, pero extirpando un cartílago costal, se abre una ventana de acceso al mediastino anterior por donde se puede tomar una biopsia directamente de la masa. Este método también permite introducir el mediastinoscopio y biopsiar ganglios de la ventana aórtica.

\section{Citología por aspiración transtorácica con aguja fina}

Su uso está condicionado en gran medida a la existencia de un servicio de patología con experiencia en el análisis de la muestra y tiene en general muchas limitaciones para tratamiento y manejo de los casos.

\section{Biopsia por punción transtorácica}

Útil cuando se presenta el paciente con una masa pulmonar que hace contacto o invade la pared torácica o en estudio de lesiones periféricas.

Se introduce una aguja gruesa o trocar (thru-cut) para obtener una biopsia. Es también una opción en casos en que el paciente no es candidato para tratamiento quirúrgico o que rehuse la misma.

\section{Toracotomía exploradora}

Cuando no se puede llegar a un diagnóstico por los métodos 
menos invasivos o cuando hay duda sobre la resecabilidad de una lesión, está perfectamente indicado practicar una toracotomía.

El rastreo previo por metástasis, el estudio de la condición cardiopulmonar del paciente, el soporte para el cuidado postoperatorio y la factibilidad de una biopsia por congelación, son elementos fundamentales para realizarla.

\section{Clasificación Histológica}

Las neoplasias primarias del pulmón se clasifican de acuerdo a la Organización Mundial de la Salud en:

1. Carcinoma escamoso o epidermoide, que puede subclasificarse como bien, mediana o pobremente diferenciado.

2. Adenocarcinoma, dentro de los cuales se pueden categorizar el acinar, el papilar y el bronquiolo alveolar.

3. Carcinoma indiferenciado de células pequeñas, dentro de los cuales se encuentran las variedades de células en avena o tipo lifocítico, el tipo intermedio o fusiforme o poligonal y mezclas de estos tipos celulares.

4. Carcinoma indiferenciado de células grandes, con queratinización, mucina extracelular y formación de acinos o glándulas.

5. Tumores mixtos, que corresponden a neoplasias en las que se demuestran áreas con patrones de los dos primeros tipos celulares mencionados.

Los otros tipos histológicos que representan menos del 10\%, tienen características particulares por lo que se protocolizarán individualmente.

El primer paso para organizar el manejo del cáncer pulmonar es solicitar a los patólogos que reporten estas neoplasias con base a la clasificación señalada por la Organización Mundial de la Salud, categorizándolos primero dentro de uno de los cuatro tipos histológicos y agregándole la variedad si es posible. Igualmente importante es el informe de los ganglios linfáticos y los bordes del tumor.

\section{Estudio de las Metástasis}

Los sitios más frecuentes a donde metastatiza el cáncer pulmonar son:

\section{Intratorácicas:}

1. A los ganglios del mediastino

2. Al mismo pulmón

3. Al pulmón contralateral

4. A la pleura
Extratorácicas:

1. $\mathrm{Al}$ cerebro

2. Al hígado

3. A hueso

4. A suprarrenales

5. A riñones

\section{Estudio de las metástasis intratorácicas:}

Como ya se mencionó, la TAC es un excelente método para detectar nódulos pulmonares pequeños y adenomegalias mediastinales, por lo que es de elección para descartar las metástasis intratorácicas.

\section{Estudio de las metástasis a hueso:}

La clínica junto con la fosfatasa alcalina y el calcio son apropiados para detectar la presencia de una lesión osteolítica. En caso de existir una sospecha, se puede aclarar con un gama óseo o una radiografía con foco en el área específica.

\section{Estudio de las metástasis a cerebro:}

Hay acuerdo entre varios autores en dejar la TAC sólo para casos en que la historia clínica o el examen físico sugieren una posible alteración a nivel del sistema nervioso central y en todos los casos de tumores de células pequeñas.

\section{Estudio de las metástasis intra-abdominales}

El U.S. de abdomen en manos experimentadas, es suficiente para descartar metástasis a hígado y riñones; sin embargo las suprarrenales pasan inadvertidas en la mayoría de los estudios de US, por tal motivo, se ha convenido dentro del protocolo para la TAC de tórax tomar de rutina cortes de suprarrenales, para aclarar este sitio.

\section{Clasificación TNM para el cáncer pulmonar}

\section{Tumor Primario (T)}

Tx: Tumor que ha sido detectado por presencia de células malignas en la secreción bronquial, pero no se visualiza en las radiografías ni en la broncoscopía o tumor que no puede ser evaluado.

T0: Cuando no hay evidencia de tumor primario.

Tis: Carcinoma in situ.

T1: Tumor de $3 \mathrm{~cm}$. o menos de diámetro, rodeado de pulmón o pleura visceral, sin evidencia de invasión a un bronquio lobar en la broncoscopia.

T2: Tumor mayor de $3 \mathrm{~cm}$ de diámetro o de cualquier tamaño cuando invade la pleura visceral o un bronquio principal o se asocia con atelectasia o neumonitis obstructiva que 
se extiende al hilio pero que no afecta todo el pulmón . En la broncoscopía la invasión proximal debe extenderse a más de $2 \mathrm{~cm}$. de la carina.

T3: Tumor de cualquier tamaño con extensión directa a pared torácica, diafragma, pleura mediastinal o pericardio parietal o cuando se extiende a menos de $2 \mathrm{~cm}$. de la carina sin invadirla o cuando se asocia con atelectasia o neumonitis obstructiva de todo el pulmón.

T4: Tumor de cualquier tamaño con invasión del corazón, grandes vasos, tráquea, esófago, cuerpo vertebral, carina, cuando se acompaña de un derrame pleural maligno o cuando existen nódulos tumorales satélites en el mismo lóbulo.

\section{Compromiso ganglionar (N)}

NX: Los ganglios regionales no son evaluables

N0: No hay metástasis demostrables a ganglios linfáticos.

N1: Metástasis a ganglios intrapulmonares, peribronquiales o hiliares ipsilaterales.

N2: Metástasis a ganglios mediastinales ipsilaterales o a los de la subcarina

N3: Metástasis a ganglios contralaterales o a supraclaviculares o escalenos ipsi o contralaterales.

\section{Metástasis (M)}

MX: No puede evaluarse la presencia de metástasis.

M0: No hay metástasis conocidas a distancia.

M1: Hay metástasis distantes, incluyendo a otro lóbulo pulmonar ipsi o contralateral.

\section{Estadios (E)}

$\begin{array}{llll}\text { Carcinoma oculto } & \text { TX } & \text { N0 } & \text { M0 } \\ \text { Estadio 0 } & \text { T1S } & \text { N0 } & \text { M0 } \\ \text { Estadio IA } & \text { T1 } & \text { N0 } & \text { M0 } \\ \text { Estadio IB } & \text { T2 } & \text { N0 } & \text { M0 } \\ \text { Estadio IIA } & \text { T1 } & \text { N1 } & \text { M0 } \\ \text { Estadio IIB } & \text { T2 } & \text { N1 } & \text { M0 } \\ & \text { T3 } & \text { N0 } & \text { M0 } \\ \text { Estadio IIIA } & \text { T1 } & \text { N2 } & \text { M0 } \\ & \text { T2 } & \text { N2 } & \text { M0 } \\ & \text { T3 } & \text { N1, N2 } & \text { M0 } \\ \text { Estadio IIIB } & \text { Cualquier T } & \text { N3 } & \text { M0 } \\ & \text { T4 } & \text { Cualquier N } & \text { M0 } \\ \text { Estadio IV } & \text { Cualquier T } & \text { Cualquier N } & \text { M1 }\end{array}$

\section{Tratamiento del Cáncer Pulmonar}

El único método que puede ofrecer curación a un paciente portador de un cáncer pulmonar, es la resección quirúrgica.

La quimioterapia tiene un papel importante como terapia adyuvante en el carcinoma de células no pequeñas y en el tratamiento primario del carcinoma de células pequeñas.

La radioterapia es efectiva para reducir el volumen tumoral pre-quirúrgico en el tumor del ápex pulmonar y para disminuir la frecuencia de recurrencia local como terapia adyuvante a la cirugía.

La efectividad de la cirugía depende directamente del estadio en que se encuentre la enfermedad.

La clasificación TNM fue diseñada de tal manera que los tumores en estadios I, II y IIIA son susceptibles de ser extirpados quirúrgicamente y el IIIB y IV aunque lo fuesen, se acompañan de una morbi-mortalidad tan alta que no justifica la cirugía, sólo que se trate de una condición muy especial.

\section{Estadios I y II}

La lobectomía y la neumonectomía son las operaciones indicadas para la resección quirúrgica de los tumores en estadio I y II, dependiendo de la localización, extensión y compromiso ganglionar de la lesión. Resecciones menores como segmentectomías o cuñas, están indicadas para la cirugía de metástasis o en pacientes con enfermedad cardiopulmonar o con una limitación funcional tal, que no permite una resección mayor.

La disección ganglionar (hiliares, traqueobronquiales, subcarina, ligamento pulmonar inferior y de la ventana aórtica) debe hacerse de rutina, para clasificar con más precisión el estadio postoperatorio y decidir la necesidad de tratamiento adyuvante.

\section{Estadio IIIA}

El estadio IIIA requiere una lobectomía o neumonectomía con resección en bloque de la estructura involucrada, ya sea pared torácica, diafragma, pericardio o pleura. Es recomendable dejar buenos márgenes de resección y marcarlos para orientar la radiación adyuvante, se recomiendan $5 \mathrm{~cm}$ de margen en las costillas infiltradas y una costilla sana por arriba y por abajo. El defecto en la pared o en el diafragma puede ser reparado adecuadamente con malla de polipropilene.

\section{Estadios IIIB y IV}

Los estadios IIIB y IV se salen de las posibilidades quirúrgicas regulares, por lo que debe considerarse la quimioterapia, radioterapia o solamente tratamiento paliativo.

La aplicación de quimio y radioterapia postoperatoria en pacientes con resección completa, sin enfermedad residual no esta indicada. Sin embargo la combinación de ambas en 
pacientes con resección macroscópicamente completa, pero que se demuestra enfermedad residual histológica en márgen de resección o ganglios mediastinales, ha demostrado mejorar el intervalo libre de enfermedad aunque no la sobre vida global.

\section{Terapia de inducción}

Los tumores del ápex pulmonar representan una situación particular ya que crecen silenciosamente sin dar síntomas ni metástasis hasta que han alcanzado gran tamaño, por lo que es conveniente irradiarlos antes de la cirugía para disminuir el volumen tumoral y mejorar las posibilidades de resección.

Lo mismo se ha planteado para tumores que clínicamente se han clasificado como IIIA, pero hay sospecha que sean técnicamente difíciles de resecar por su posición o cercanía con las estructuras del hilio pulmonar. La aplicación de quimiotera-pia y radioterapia neoadyuvante ha demostrado mejorar el porcentaje de resecciones y la supervivencia.

\section{Contraindicaciones para Cirugía}

Existen indicadores que permiten predecir que una lesión no va a ser resecable o que aunque se haga, el pronóstico es tan malo que no se justifica hacerlo. Estos indicadores ampliamente aceptados se indican a continuación pero no deben valorarse aisladamente, sino haciendo unidad clínica, porque podrían no estar relacionados con el tumor y tener otra etiología:

\section{Por examen físico:}

1. Ronquera (por parálisis de cuerda vocal izquierda)

2. Adenomegalias supraclaviculares metastásicas

3. Síndrome de vena cava superior (por invasión tumoral)

4. Síndrome de Hörner (por invasión del plexo simpático)

5. Hepatomegalia metastásica

\section{Por broncoscopía}

1. Cuando hay parálisis de la cuerda vocal izquierda y se han detectado adenomegalias en la ventana aórtica, por invasión del nervio laríngeo inferior.

2. Cuando el tumor invade la tráquea

3. Cuando invade la carina

4. Cuando hay tumor bilateral

\section{Por radiografía}

1. Presencia de derrame pleural maligno.

2. Enfermedad tumoral bilateral.

\section{Por TAC}

1. Derrame pleural maligno.

2. Enfermedad tumoral bilateral.

3. Adenomegalias mediastinales malignas.

4. Cuando la lesión rodea completamente una estructura vital.

5. Cuando hay invasión de columna vertebral.

6. Derrame pericárdico.

7. Invasión de los vasos pulmonares en el hilio (puede confirmarse por arteriografía).

\section{Referencias}

1. Shields, T. General Thoracic Surgery. Cuarta Edición. Williams \& Wilkins. USA. 1994

2. Pearson, F. Thoracic Surgery. USA. 1995

3. Pearson, F. Seminars in Thoracic and Cardiovascular Surgery. Vol 4, No.1. Enero 1992

4. Benfield, J. Chest Surgery Clinics of North America. Febrero 1992. 
ISSN 0001-6002/2003/Supl.1/40-41

Acta Médica Costarricense,(C2003

Colegio de Médicos y Cirujanos

\section{Tumores de Mediastino}

José Mauricio Arce-Quesada, Raúl Valverde-Robert

Asociación Costarricense de Neumología y Cirugía de Tórax

\section{Definición}

Mediastino: Espacio virtual con los siguientes limites anatómicos:

Anterior Cara posterior del esternón.

Posterior Cara anterior de los cuerpos vertebrales

Lateral Las pleuras mediastínicas

Inferior El diafragma

Superior Línea transversal que va desde la articulación del manubrio esternal al borde inferior de

T4.

\section{Clasificación}

Inicialmente se dividió en cuatro compartimientos: anterior, superior, medio y posterior. Actualmente se divide en antero superior $\mathrm{o}$ anterior, medio o visceral y posterior $\mathrm{o}$ paravertebral.

Las lesiones tumorales que se localizan de acuerdo al compartimiento mediastinal son:

\begin{tabular}{|l|l|l|}
\hline $\begin{array}{l}\text { Anterior o } \\
\text { anterosuperior }\end{array}$ & $\begin{array}{l}\text { Visceral } \\
\text { o medio }\end{array}$ & $\begin{array}{l}\text { Paravertebral } \\
\text { o posterior }\end{array}$ \\
\hline $\begin{array}{l}\text { Timoma o quistes } \\
\text { tímicos }\end{array}$ & Linfoma & $\begin{array}{l}\text { Tumores } \\
\text { neurogénicos }\end{array}$ \\
\hline $\begin{array}{l}\text { Tumor células } \\
\text { germinales }\end{array}$ & $\begin{array}{l}\text { Quistes pericárdico, } \\
\text { entérico, mesotelial, } \\
\text { neurogénico o del } \\
\text { conducto torácico. }\end{array}$ & Fibrosarcoma \\
\hline Linfoma & Granulomas & Feocromocitoma \\
\hline Linfangioma & Hamartoma & Linfoma \\
\hline Hemangioma & Paraganglioma & \\
\hline Lipoma & Feocromocitoma & \\
\hline Fibroma & & \\
\hline Adenoma Paratiroideo & & \\
\hline $\begin{array}{l}\text { Tiroides ectópico o } \\
\text { con proyección intra } \\
\text { torácica }\end{array}$ & & \\
\hline
\end{tabular}

\section{Criterios Diagnósticos}

Síntomas compresivos:

Vía respiratoria disnea, tos, estridor y ocasionalmente hemoptisis

Vía digestiva disfagia

Vascular síndrome de vena cava superior

Nerviosa dolor, Síndrome de Horner y trastornos sensitivos y/o motores

Pleural derrame

Pericárdica derrame pericárdico y/o taponamiento cardiaco.

Un 50\% son asintomáticos y el hallazgo es incidental.

\section{Exámen de gabinete}

Radiografía PA y lateral de tórax

\section{Criterios de ingreso}

Tumor de mediastino confirmado radiológicamente

Exámenes de laboratorio y gabinete iniciales:

1. Hemograma completo

2. Grupo Rh

3. Pruebas de coagulación

4. Pruebas de función renal

5. TAC de tórax y abdomen superior con medio de contraste (cuando sea posible)

6. Ultrasonido de abdomen

7. Broncoscopia

8. Pruebas de función respiratoria 
Para tumores de mediastino antero superior y medio se pueden agregar los siguientes estudios:

1. Marcadores tumorales: DHL, unidad subBeta de gonadotropina coriónica y la alfa feto proteína

2. Ultrasonido de cuello

3. Gama de tiroides

4. Pruebas de función tiroidea

En caso de disfagia se puede solicitar un esofagograma.

La resonancia magnética puede ser de utilidad para tumores de mediastino posterior con compromiso vertebral así como para aquellos pacientes que son alérgicos al medio de contraste pues este estudio nos permite diferenciar las estructuras vasculares al resto de los tejidos.

La angiografía se utiliza cuando se sospecha que la lesión es de origen vascular.

El ecocardiograma es de utilidad cuando existe compromiso pericárdico.

\section{Manejo intrahospitalario}

Se debe intentar obtener el diagnóstico histológico en la mayoría de los tumores de mediastino antero-superior y medio mediante mediastinoscopía, mediastinostomía o toracoscopía, dependiendo de la localización tumoral.

En los tumores de mediastino posterior el manejo es diferente, debido al tipo de tumor de este compartimiento, por lo que se realiza toracotomía postero lateral o toracoscopía con biopsia por congelación y eventual resección. En los casos con contraindicación quirúrgica se puede indicar biopsia por punción dirigida por TAC o por ultrasonido.

\section{Criterios de egreso}

1. Comprobación del diagnóstico histológico.

2. Resección o citorreducción en caso de que el manejo sea quirúrgico.

3. Coordinar inicio de quimioterapia de inducción o coadyuvante en los casos que lo requieran.

4. Coordinar inicio de radioterapia de emergencia en el caso de Síndrome de vena cava superior o como manejo terapéutico en los casos que así lo ameriten.

\section{Referencias}

1. Shields, T. General Thoracic Surgery. Cuarta Edicion. Williams \& Wilkins. USA .1994

2. Pearson, F. Thoracic Surgery. USA. 1995

3. Pearson, F. Seminars in Thoracic and Cardiovascular Surgery. Vol 4, No.1. Enero 1992

4. Benfield, J. Chest Surgery Clinics of North America. Febrero 1992. 
ISSN 0001-6002/2003/Supl.1/42-48

Acta Médica Costarricense,(C2003

Colegio de Médicos y Cirujanos

\title{
Fibrosis Quística
}

\author{
Arturo Solís-Moya, José Pablo Gutiérrez-S. \\ Asociación Costarricense de Neumología y Cirugía de Tórax
}

\section{Introducción}

El manejo de los pacientes pediátricos con Fibrosis Quística (FQ), es un proceso dinámico y complejo que requiere un alto nivel de conocimientos clínicos y científicos para poder brindar al paciente las mejores opciones terapéuticas que se ofrecen alrededor del mundo, manteniendo siempre un estricto control de análisis de la información disponible y siguiendo los principios que exige la práctica de medicina basada en la evidencia.

El presente documento pretende tan sólo esbozar los lineamientos generales que se deben seguir en el Hospital Nacional de Niños “Dr.Carlos Sáenz Herrera”, para el manejo multidisciplinario de los niños con FQ.

\section{Equipo interdisciplinario}

El manejo del paciente con FQ debe ser siempre interdisciplinario. Una patología tan compleja como la FQ y las repercusiones en el niño que la padece, así como en su entorno familiar, social y económico exigen la intervención pronta y oportuna de diferentes profesionales de la salud.

Un equipo interdisciplinario para la atención de niños con FQ debe estar conformado por: Médico Pediatra Neumólogo, Enfermeras, Fisioterapeuta Respiratorio, Nutricionista, Trabajadora Social, Psicólogo Clínico, Farmacéutico.

Con cierta frecuencia este equipo también requiere la ayuda y consejo de algunas otros especialistas como son el Cirujano Pediatra, el Gastroenterólogo, Inmunólogo, Infectólogo, etc.

\section{Presentación de la enfermedad}

La FQ se presenta al clínico en tres formas principales.

\section{Ileo meconial.}

El íleo meconial (IM) está presente en un 15\% a 20\% de los niños con FQ. Todo niño con IM tiene FQ hasta que no se demuestre lo contrario y por ende, en neonatos con esta entidad médico-quirúrgica, se debe realizar un test de cloruros en sudor en forma urgente.

\section{Malabsorción Intestinal.}

Aproximadamente un 95\% de los pacientes con FQ tienen malabsorción intestinal; en la mayoría esto es evidente desde la lactancia. La causa principal es una deficiencia severa de enzimas pancreáticas.

\section{Infecciones del tracto respiratorio bajo (ITRB).}

Virtualmente todos los pacientes con FQ tienen ITRB, usualmente desde una edad temprana.

Otras entidades clínicas que pueden ser la forma de presentación de la FQ son hepatopatía crónica o neonatal, pólipos nasales, asma rebelde al tratamiento, prolapso rectal, shock por depleción de sodio, infertilidad masculina o ganancia ponderal inadecuada.

\section{Diagnóstico de la fibrosis quística}

El diagnóstico de la FQ descansa en la presencia de una cantidad excesiva de sodio y cloruro en el sudor de un individuo que tiene manifestaciones clínicas compatibles con FQ.

Todo niño en el que se sospeche FQ debe someterse al examen de cloruros en sudor. Para este examen el paciente recibe una cita programada en el hospital y coordinada por el laboratorio de bioquímica.

Actualmente se acepta como test de cloruros positivo aquel con niveles de cloruro mayores a $60 \mathrm{mEq} / \mathrm{L}$, siempre y cuando la cantidad de sudor recolectada sea igual o mayor a $100 \mathrm{mg}$. Los niveles de cloruro considerados positivos son motivo de controversia en la actualidad y por ello, ante la duda sobre su significado clínico, el resultado debe ser discutido con el Pediatra Neumólogo.

Todo paciente con un test de cloruros positivo debe someterse a una segunda prueba confirmatoria.

La comunicación del diagnóstico de FQ a los padres del paciente es obligación y responsabilidad directa del Pediatra Neumólogo. Ningún otro profesional en salud debe abordar a los padres para comunicarles el diagnóstico.

Actualmente no contamos con los recursos técnicos para realizar tamizaje neonatal por FQ ni para establecer el genotipo mutacional de nuestros pacientes, pero se están realizando esfuerzos para superar esta deficiencia. 


\section{Precauciones generales para los niños con FQ}

Existen una serie de precauciones razonables que deben ser observadas por el paciente con FQ y por su familia.

1. Inmunización contra sarampión, parotiditis, rubeola, tos ferina y Haemophilus influenzae. La FQ no es una contraindicación para que el niño reciba la BCG.

2. Evitar el fumado activo y pasivo.

3. Evitar el ingreso a guarderías a una edad muy temprana.

4. Evitar el contacto con amigos y/o familiares que cursen con cuadros gripales.

5. Evitar el contacto cercano con lugares donde se críen animales de granja o se acumule vegetación putrefacta.

6. Evitar la participación en actividades de grupo (como campamentos, fiestas, etc.) con otros pacientes con FQ.

\section{Seguimiento del paciente con FQ}

El equipo multidisciplinario del Hospital Nacional de Niños atiende a los pacientes con FQ en forma quincenal, con citas en la consulta externa del hospital los días viernes únicamente.

El paciente es valorado en forma integral por los diferentes especialistas y miembros del equipo y, posteriormente, se realiza una reunión para discutir en conjunto todos y cada uno de los niños atendidos ese día.

Dentro de las múltiples intervenciones que se realizan los días de consulta se pueden citar las siguientes:

a) Historia clínica y examen físico completo por parte del Pediatra Neumólogo.

b) Valoración antropométrica y nutricional.

c) Revisión del estado de inmunización actual.

d) Pruebas de función pulmonar en niños mayores de 5 años de edad.

e) Prueba con broncodilatadores (en casos especiales).

f) Valoración por fisioterapeuta.

g) Contacto con trabajo social.

h) Radiografías de tórax y/o abdomen (en casos especiales).

i) Cultivo de esputo o frotis faríngeo.

j) Exámenes de laboratorio.

k) Revisión exhaustiva de los medicamentos prescritos.
Otro tipo de análisis e investigaciones paraclínicas pueden ser realizadas en forma anual. Entre ellas se citan las siguientes:

a) Pruebas de función hepática.

b) Curva de tolerancia a la glucosa (en niños mayores de 10 años).

c) Estudios por aspergilosis broncopulmonar alérgica.

d) Ultrasonido de abdomen.

\section{Manejo respiratorio}

Las medidas generales para minimizar la extensión y los efectos de las ITRB incluyen diagnóstico temprano, adecuada nutrición, exposición mínima a ITRS, garantizar una adecuada inmunización y evitar el fumado activo y pasivo.

El manejo respiratorio del niño con FQ descansa básicamente en dos pilares:

1. Manejo racional y "agresivo" de los antibióticos, ya sea por VO o por vía IV.

2. Fisioterapia de tórax.

Otras medidas o intervenciones desde el punto de vista respiratorio que a menudo se utilizan en los pacientes con FQ son: uso de corticoesteroides tópicos y/o sistémicos, drogas nebulizadas (broncodilatadores, solución salina, antibióticos y otros), oxígeno suplementario, etc.

Es sumamente importante que todos los pacientes sean valorados por un fisioterapeuta respiratorio tan pronto como se establezca el diagnóstico.

La fisioterapia de tórax es parte integral del manejo de la FQ. Los objetivos principales son la reducción de la obstrucción de la las vías respiratorias al mejorar el aclaramiento de secreciones traqueobronquiales, reducir la severidad de la infección al eliminar material infectado de las vías respiratorias y mantener una función respiratoria óptima con tolerancia al ejercicio adecuada.

Es importante que el tratamiento sea apropiado para la edad del paciente, su situación familiar y social, y la severidad de su enfermedad.

\section{Manejo gastrointestinal y nutricional}

La secreción de jugo pancreático está severamente reducida en la mayoría de pacientes con FQ desde una edad temprana y, de no tratarse con enzimas pancreáticas, la digestión y la absorción de nutrientes se vería gravemente comprometida. La absorción inadecuada de nutrientes desde el intestino lleva al paciente a sufrir de síntomas digestivos recurrentes, malnutrición, crecimiento deficiente, y de carencias vitamínicas específicas. 
Existe una amplia evidencia clínica de que los pacientes con FQ bien nutridos tienen mejor pronóstico y calidad de vida. Es por ende esencial que los niños con FQ tengan un adecuado soporte nutricional, con aporte calórico apropiado, enzimas pancreáticas suplementarias y suministro de vitaminas liposolubles.

En ocasiones es necesario administrar suplementos dietéticos o realizar intervenciones más agresivas como alimentación por sonda nasogástrica (SNG) o a través de gastrostomía.

Otros aspectos de gran importancia dentro de esta área son la detección temprana de Diabetes Mellitus (DM), enfermedad hepática, enfermedad ulceropéptica y diarrea crónica.
La ganancia pondoestatural del paciente con FQ debe ser cuidadosamente monitorizada en todas las vistas del paciente al hospital, tanto en la consulta externa como a la hora de una hospitalización.

\section{Atención de enfermería}

La participación de enfermería en el cuidado de los niños con FQ es fundamental. En esta área se cumplen una serie de intervenciones de enorme importancia, tanto a nivel clínico como a nivel social.

La enfermera tiene además una participación muy activa en lo que se refiere a la educación continua del paciente y de su familia.

\section{Criterios de atención de enfermería. Criterios de desempeño para la atención de niños con fibrosis quística}

1. La enfermera cumple el cuidado de enfermería del niño con fibrosis quística.
1.1 Identifica al niño en su intervención a través de: expediente.

1.2 Orienta e informa a los padres sobre normas y rutinas de la consulta y estado de salud del niño.

1.3 Anota datos generales del niño:

- Procedencia

- Sexo

- $\quad$ Edad

- Actividad

- Estado anímico

- $\quad$ Apetito

- Tos

- Hipocratismo digital

- Esputo

- Disnea con el ejercicio

- Disnea en reposo

- Número de deposiciones

- Características de las deposiciones

1.4 Toma y valora:

- Temperatura

- Peso

- Talla

- PA

- Frecuencia Cardíaca

- Frecuencia Respiratoria

- $\quad$ Saturación de oxígeno

- Medición de pico flujo

- $\quad$ Pruebas de función pulmonar

1.5 Identifica y valora los signos y síntomas de problemas respiratorios

- Sibilancias

- Crépitos

- Roncos

- Disminución del murmullo vesicular

- Taquipnea

- Taquicardia

- Aleteo Nasal

- Disnea

- Palidez

- Cianosis

- Retracciones 


\begin{tabular}{|c|c|}
\hline & $\begin{array}{l}\text { 1.6 } \text { Valora la presencia de problemas digestivos: } \\
\text { - } \quad \text { Estreñimiento o diarrea } \\
\text { - } \quad \text { Oclusión intestinal } \\
\text { 1.7 } \quad \text { Síndrome de mala absorción valora } \\
\text { resultados de exámenes de laboratorio } \\
\text { - } \quad \text { Hemograma } \\
\text { - } \quad \text { Cloruros en Sudor } \\
\text { - } \quad \text { Conutos } \\
\text { 1.8 Planifica la atención de enfermería } \\
\text { - } \quad \text { Identifica los diagnósticos de enfermería } \\
\text { - } \quad \text { Transcribe y cumple medicación prescrita } \\
\text { - } \quad \text { Hace referencia para el seguimiento a otro } \\
\text { - } \quad \text { Particicipa a los padres en el cuidado del niño } \\
\text { incluyendo el seguimiento. } \\
\text { 1.9 Anota el progreso del niño, medicamentos, } \\
\text { tratamiento y la enseñanza impartida. } \\
\text { 1.10 Coordina con el resto del equipo si se } \\
\text { requiere intervención inmediata. } \\
\text { 1.11 Contesta las preguntas de la madre con } \\
\text { amabilidad. } \\
\text { 1.12 Hace intervención en crisis. }\end{array}$ \\
\hline $\begin{array}{l}\text { 2. El personal de enfermería recibe } \\
\text { educación sobre el cuidado del niño } \\
\text { con fibrosis quística. }\end{array}$ & $\begin{array}{l}\text { 2.1 La enfermera realiza actividades de } \\
\text { educación sobre F.Q., con el equipo para } \\
\text { enfermeras, auxiliares, otros, tomando en } \\
\text { cuenta: problemática, fisiopatología, signos y } \\
\text { síntomas, tratamiento, criterios de atención de } \\
\text { Enfermería. }\end{array}$ \\
\hline $\begin{array}{l}\text { 3. Los usuarios reciben educación en } \\
\text { salud sobre el cuidado del niño con } \\
\text { fibrosis quística. }\end{array}$ & $\begin{array}{l}\text { 3.1 La enfermera enseña al niño y a la familia } \\
\text { - } \quad \text { Razon siguientes aspectos: } \\
\text { consulta de F.Q. } \\
\text { - } \quad \text { Enseña signos y síntomas de reagudización } \\
\text { de los problemas respiratorios } \\
\text { - } \quad \text { Enseña signos y síntomas que ameriten llevar } \\
\text { al niño al hospital } \\
\text { - } \quad \text { Administración de medicamentos. } \\
\text { - } \quad \text { Nso adecuado de enzimas pancreáticas } \\
\text { - } \quad \text { Fisioterapiones de tórax } \\
\text { - } \quad \text { Flutter y otras técnicas de higiene bronquial } \\
\text { - Enseña consejo genético } \\
\text { - La enfermera recibe retroalimentación } \\
\text { de la madre sobre la enseñanza impartida. }\end{array}$ \\
\hline $\begin{array}{l}\text { 4. La enfermera participa con el equipo } \\
\text { de salud en la búsqueda de recursos } \\
\text { necesarios para brindar una atención de } \\
\text { calidad al niño con fibrosis quística. }\end{array}$ & $\begin{array}{l}\text { 4.1 La enfermera identifica y analiza } \\
\text { las áreas de mejoramiento con el equipo. } \\
4.2 \text { Identifica las necesidades de la clínica de } \\
\text { fibrosis quística } \\
\begin{array}{l}\text { 4.3 Ejecuta acciones de mejoramiento con el } \\
\text { equipo }\end{array} \\
\begin{array}{l}\text { 4.4 Coordina con la Asociación Costarricense de } \\
\text { F.Q. el apoyo necesario para resolver los } \\
\text { problemas del niño. }\end{array}\end{array}$ \\
\hline $\begin{array}{l}\text { 5. Aplica el auditoraje, control y supervisión } \\
\text { de la enseñanza impartida a los padres y } \\
\text { a los niños con fibrosis quística. }\end{array}$ & $\begin{array}{l}\text { 5.1 La enfermera hace evaluaciones y controles } \\
\text { de la enseñanza a los padres y niños con } \\
\text { fibrosis quística. }\end{array}$ \\
\hline $\begin{array}{l}\text { 6. Aplica el auditoraje, control y supervisión } \\
\text { de las tareas que realiza el personal de } \\
\text { enfermería para la atención del niño } \\
\text { con fibrosis quística. }\end{array}$ & $\begin{array}{l}\text { 6.1 La enfermera hace evaluaciones y controles } \\
\text { de las tareas que realiza el personal de } \\
\text { enfermería. }\end{array}$ \\
\hline
\end{tabular}




\section{Hospitalización de pacientes con Fibrosis Quística}

Los niños con FQ deben ser hospitalizados con cierta regularidad, ya sea en forma electiva (para recibir antibióticos endovenosos, realización de estudios complejos, cirugía, etc.) o por exacerbación pulmonar aguda o deterioro de algún otro sistema.

La mayoría de los pacientes que se hospitalizan provienen de la consulta externa de nuestro servicio. Debe reportarse al Pediatra Neumólogo en disponibilidad la admisión de niños con FQ durante el horario extraordinario.

Los pacientes con FQ deben ser hospitalizados en las camas del Servicio de Neumología, salvo en condiciones especiales que contraindiquen dicha medida.

En la gran mayoría de los casos estos pacientes van a requerir terapia antibiótica endovenosa, $\mathrm{y}$ en nuestro medio disponemos de drogas tales como amikacina, ceftazidime, oxacilina, ceftriaxone, y otros; existe una alta prevalencia de Pseudomonas aeruginosa entre nuestros pacientes fibroquísticos por lo cual la cobertura antibiótica debe ser apropiada.

En términos generales los criterios para hospitalizar a un niño con FQ son:

1. Aumento en la frecuencia de la tos productiva.

2. Aumento en la cantidad y/o cambios en la apariencia del esputo.

3. Aumento en la frecuencia respiratoria.

4. Aparición de disnea durante el reposo.

5. Hipoxia (por oximetría de pulso).

6. Disminución marcada del murmullo vesicular.

7. Aparición de nuevos cambios en la radiografía de tórax.

8. Deterioro en las pruebas de función pulmonar.

9. Pérdida de peso o ganancia ponderal inadecuada.

10. Hemoptisis.

Otras condiciones médicas que escapan a la lista anterior deben ser valoradas

individualmente. El sentido común debe ser la norma a la hora de tomar la decisión de hospitalizar a un paciente con FQ.

El tratamiento del paciente fibroquístico hospitalizado tiene como objetivo cuatro aspectos fundamentales:

1. Mejorar la condición nutricional del paciente.

2. Administrar fisioterapia de tórax en forma regular, al menos tres veces al día.
3. Manejo de la infección.

4. Educación al paciente.

Todo paciente mayor de 5 años que requiera hospitalización debe realizar pruebas de función pulmonar previas al internamiento y su egreso.

Idealmente, luego de 14 días de hospitalización, tanto el peso como la espirometría del paciente deben mejorar.

\section{Problemas psicosociales.}

No es sorprendente que una enfermedad tan seria como la $\mathrm{FQ}$, que requiere tratamiento diario, visitas frecuentes al hospital e internamientos, se asocie con niveles considerables de estrés emocional para el paciente y su familia. La mayoría de pacientes y familiares logran lidiar con la enfermedad en forma muy adecuada, pero pueden requerir ayuda sobre todo en situaciones críticas tales como el momento del diagnóstico, inicio de la escuela, hospitalizaciones, adolescencia, deterioro de la salud y fallecimiento.

\section{Transferencia a centro de adultos.}

Actualmente el equipo multidisciplinario de FQ del Hospital Nacional de Niños está desarrollando las políticas y contactos necesarios para que nuestra población pediátrica pueda ser transferida a un centro de pacientes adultos donde se brinde una atención de alta calidad y se establezca una adecuada continuidad entre nuestra labor y la de nuestros colegas.

La edad para transferir nuestros pacientes a un centro de adultos debe considerarse alrededor de los 16 años.

\section{Planes para el futuro.}

El Servicio de Neumología del Hospital Nacional de Niños desea desarrollar las siguientes áreas dentro del manejo de nuestros pacientes con FQ:

1. Tamizaje neonatal.

2. Adquisición de nuevos antibióticos anti-pseudomona.

3. Diagnóstico específico de las mutaciones de la proteína CFTR.

4. Tamizaje de DM en forma rutinaria.

\section{Farmacia.}

Flory Hidalgo Solano

Farmacéutica, Jefe División de Farmacia de Consulta Externa.

Los pacientes con FQ requieren una serie de medicamentos indispensables para el mantenimiento de sus funciones biológicas normales, o bien para controlar fenómenos tales como las infecciones recurrentes y los procesos inflamatorios crónicos de las vías aéreas. 
Evitar la "polifarmacia" es difícil en estos pacientes con una patología tan compleja; sin embargo el médico debe mantener, en coordinación con Farmacia, un control estricto y adecuado de los medicamentos que se entregan al paciente fibroquístico y de la dosificación especial a la cual se prescriben estos fármacos.

La farmacocinética en el paciente con FQ es diferente a la de otros pacientes por cuanto la absorción está reducida. Por esta razón los pacientes fibroquísticos requieren una dosificación especial para la mayoría de los medicamentos que reciben.

A continuación se brinda una lista de medicamentos "básicos" utilizados en nuestro servicio para el manejo de la FQ. Debe entenderse que estas dosis corresponden exclusivamente a pacientes con FQ y no deben ser utilizadas para el manejo de otras patologías fuera de la FQ.

\section{Amikacina}

Dosis

Infantes y niños: 15-22.5 mg / Kg / 24 hr. Ž c/8 hr. IV / IM

Adultos:

15 mg / Kg / 24 hr. Ž c/8 - 12 hr. IV / MI

Presentación: Vial $100 \mathrm{mg} / 2$ cc у $500 \mathrm{mg} / 2$ cс.

\section{Amoxilina}

Dosis

Niños: $\quad 20-60 \mathrm{mg} / \mathrm{Kg} / 24 \mathrm{hr} \div \div \mathrm{c} / 8 \mathrm{hr}$. VO

Adultos: $\quad 250$ - 500 mg c/8 Dosis Máx.: 2 - 3 g/día.

Presentación: Suspención 250 mg / 5 cc.; Tabletas 500 mg.

\section{Ceftazidime}

\section{Dosis}

Infantes y niños: $150 \mathrm{mg} / \mathrm{Kg} / 24 \mathrm{hr} . \div \mathrm{c} / 8 \mathrm{hr}$. IV / IM

Adultos: $\quad$ Dosis Máx. : 6 g /24 hr.

Presentación: Vial $1 \mathrm{~g}$.

\section{Ciprofloxacina}

Dosis

Vía Oral: $\quad 40 \mathrm{mg} / \mathrm{Kg} / 24 \mathrm{hr} . \div \mathrm{c} / 12 \mathrm{hr}$.

Dosis Máx. : 2 g/ 24 hr.

Presentación: Tabletas 500 mg.

\section{Gentamicina}

Dosis

$$
7.5 \text { - } 10.5 \text { mg / Kg / } 24 \text { hr. } \div \text { c/8 hr. IM o IV }
$$

(En pacientes con F.Q.P. es eliminada más rápidamente)

Presentación: Amp. $80 \mathrm{mg} / 2$ cc.

\section{Oxacilina}

Dosis

Infantes y niños: 100 - $200 \mathrm{mg} / \mathrm{Kg} / 24 \mathrm{hr} . \div \mathrm{c} / 4-6 \mathrm{hr}$.

IM / IV;

Dosis Máx.: 12 g / 24 hr.

Presentación: Vial $1 \mathrm{~g}$.

\section{Trimetropin - Sulfametoxazol}

Dosis

Niños > 2 meses: 8 - 10 mg (T.M.P.) / Kg / 24 hr. $\div$ c/12 hr. $\mathrm{VO} / \mathrm{IV}$.

Adultos (> $40 \mathrm{Kg}$ ): 160 mg (T.M.P.) / dosis c/12 hr. VO / IV.

Presentación: Tabletas $800 \mathrm{mg}$ Sulfa + 160 mg T.M.P.

Suspención 200 mg Sulfa + 40 mg

T.M.P. / 5 cc.

\section{Enzimas pancreáticas}

\section{Dosis}

Infantes: $\quad 2000$ - $4000 \mathrm{U}$ lipasa / $120 \mathrm{ml}$ fórmula o cada vez que sean amamantados.

Niños < 4 años: 1000 U lipasa / Kg. / comida.

Niños > 4 años: 500 U lipasa / Kg. / comida.

La dosis total diaria incluye aproximadamente tres comidas y dos o tres meriendas por día. La dosis de las meriendas son aproximadamente la mitad de la dosis de las comidas principales.

Los requerimientos actuales son específicos para cada paciente.

Presentación: Cápsulas de 4000 U lipasa y 20000 U lipasa.

\section{Vitamina A}

Como suplemento dietético

\section{Dosis}

Infantes a 6 meses: $\quad 1500$ U / día

Niños:

$$
\begin{aligned}
& 6 \text { meses a } 3 \text { años: } 1500 \text { - } 2000 \text { U / día } \\
& 4 \text { a } 6 \text { años: } \quad 2500 \text { U / día } \\
& 7 \text { a } 10 \text { años: } \quad 3300 \text { - } 3500 \text { U / día } \\
& \text { > } 10 \text { años y adulto: } 4000 \text { - } 5000 \text { U / día }
\end{aligned}
$$




\section{Vitamina D}

Como suplemento dietético

\section{Dosis}

Infantes, niños y adultos: 400 U / día

Presentación: Frasco gotero 400 u / gota.

\section{Salbutamol}

\section{Oral:}

Niños < 6 años: 0.3 mg / Kg / 24 hr. $\div$ TID; Do.

Máx. 12 mg / 24 hr.

6 - 11 años: $6 \mathrm{mg} / 24$ hr $\div$ TID; Do. Máx.: 24 mg / 24 hr.

12 años y adultos: 2 - 4 mg / dosis TID o QID; Do. Máx.:

$$
32 \mathrm{mg} / 24 \mathrm{hr} \text {. }
$$

\section{Inhalaciones:}

Niños $<12$ años: 1 - 2 inh. 4 veces al día usando espaciador.

$>12$ años y adultos: 1 - 2 inh. cada 4 - 6 hr. Máx. 12 inh. / día.

\section{Nebulizaciones:}

$<1$ año:

$0.05-0.15 \mathrm{mg} / \mathrm{Kg} /$ dosis cada 4 - $6 \mathrm{hr}$.

1 a 5 años: 1.25 - $2.5 \mathrm{mg} /$ dosis cada 4 - $6 \mathrm{hr}$.

5 a 12 años: $2.5 \mathrm{mg} /$ dosis cada 4 - $6 \mathrm{hr}$.

$>12$ años: 2.5 - $5 \mathrm{mg} /$ dosis cada $6 \mathrm{hr}$.

Presentación:

Jarabe 2 mg / 5 cc.

Tabletas $4 \mathrm{mg}$.

Sol. Neb. 0.5\%

Aerosol 100 mcg / inh.

\section{Beclometasona}

\section{Dosis}

Niños 6 - 12 años: 1 - 2 inh. 3 - 4 veces / día (Alternativamente: 2 - 4 inh. dos veces al día); Do. Máx. 10 inh / día.

$>12$ años y adultos: 2 inh. 3 - 4 veces / día (Alternativamente: 4 inh. dos veces al día), Do. Máx. 20 inh. / día.

La dosis deben ser tituladas y ajustadas dependiendo de la respuesta del paciente.

Presentación: Aerosol 50 mcg / inh.

\section{Aztemizol}

\section{Dosis}

Niños < 6 años: 0.2 mg / Kg / 24 hr. una vez al día

6 - 12 años: 5 mg / 24 hr. una vez al día

> 12 años: $\quad 10 \mathrm{mg} / 24$ hr. una vez al día

Dosis Máx.: $10 \mathrm{mg} / 24 \mathrm{hr}$

Presentación: Tabletas de $10 \mathrm{mg}$.

\section{Prednisolona}

\section{Dosis}

Asma aguda: $\quad 2$ mg / kg / 24 hr. Ž c/ día - BID x 5 días

Dosis Máx.: $\quad 80 \mathrm{mg} / 24 \mathrm{hr}$

Presentación: Tabletas de $1 \mathrm{mg}, 5 \mathrm{mg}$ y $25 \mathrm{mg}$.

\section{Referencias}

1. Davis,P.B. Fibrosis Quística. Pediatrics in Review (en español) 2001; 22(8):257-264

2. Borowitz, D. , Baker, R.D., Stallings, V. Consensus report on nutrition for pediatric patients with cystic fibrosis. J Pediatr Gastr and Nutr 2002; 35: 246-256.

3. Cystic Fibrosis Trust, UK. Antibiotic treatment for cystic fibrosis. Report of the UK cystic fibrosis antibiotic group. Second edition, 2002.

4. Molina, M., Prieto, G., Sarría, J., Polanco, I. Fibrosis Quística: aspectos nutricionales. An Esp Pediatr 2001; 54(6):575-581.

5. $\quad$ Orenstein D, Winnie G.B., Altman H. Cystic Fibrosis: a 2002 update. J Pediatr 2002; 140(2): 156-164.

6. Wilmott RW. Making the diagnosis of cystic fibrosis. J Pediatr 1998; 132(4): 563-565.

7. Rosesnstein BJ, Cutting GR. The cystic fibrosis foundation consensus panel.The diagnosis of cystic fibrosis: a consensus statement. J Pediatr 1998; 132(4):589-595. 


\section{Editorial}

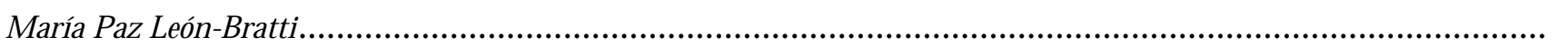

Introducción

Ronald A. Chacón Chaves .

\section{Originales}

Asma bronquial

Wing Ching Chan-Cheng, Marlene Jiménez-Carro, Sofía Antillón-Morales, Mario Ingianna-Acuña, Carlos Jaime Alfaro-Rodríguez, Georgina López-Odio, Ted Mitchell-Brumley

Enfermedad pulmonar obstructiva crónica

Ronald A. Chacón-Chaves, Mario Sibaja-Campos, Juan A. Dávila-Haas, Rodolfo Gutiérrez-Pimentel, Alexis Gutiérrez-Sanabria, Betty Rocha-Contreras, Gabriela Sánchez-Romero

Guías para el manejo de la neumonía adquirida en la comunidad (NAC) en adultos Antonio Solano, Marlene Jiménez, Carlos Dobles, Mauricio Saldarriaga, Álvaro Avilés, Juan Villalobos, Jorge Mora, Gisela Herrera, Emilio Guevara , Jorge Ramírez, Juan I Padilla, Enrique Vives, Ronald Chacón, Manuel Rojas, Bernal Cordero, Jaime Fernández, Carlos Wu, Dr. Alfredo Messino

Tumores pared torácica

Dr. Marco Herrera-Rodríguez, Dr. John Miranda-Chavarría.

Cáncer de pulmón

Dr. José A. Mainieri-Hidalgo, Dr. Alejandro Brenes-Dittel

Tumores de mediastino

Dr. José Mauricio Arce-Quesada, Dr. Raúl Valverde-Robert.

Fibrosis quística

Dr. Arturo Solís-Moya, Dr. José Pablo Gutiérrez-S. 